\title{
Transport link scanner: simulating geographic transport network expansion through individual investments
}

\author{
C. Jacobs-Crisioni ${ }^{1}$ - C. C. Koopmans ${ }^{2}$
}

Received: 27 July 2015/Accepted: 19 May 2016/Published online: 10 June 2016

(C) The Author(s) 2016. This article is published with open access at Springerlink.com

\begin{abstract}
This paper introduces a GIS-based model that simulates the geographic expansion of transport networks by several decision-makers with varying objectives. The model progressively adds extensions to a growing network by choosing the most attractive investments from a limited choice set. Attractiveness is defined as a function of variables in which revenue and broader societal benefits may play a role and can be based on empirically underpinned parameters that may differ according to private or public interests. The choice set is selected from an exhaustive set of links and presumably contains those investment options that best meet private operator's objectives by balancing the revenues of additional fare against construction costs. The investment options consist of geographically plausible routes with potential detours. These routes are generated using a fine-meshed regularly latticed network and shortest path finding methods. Additionally, two indicators of the geographic accuracy of the simulated networks are introduced. A historical case study is presented to demonstrate the model's first results. These results show that the modelled networks reproduce relevant results of the historically built network with reasonable accuracy.
\end{abstract}

Keywords Transportation · Network growth · Agent-based modelling

C. Jacobs-Crisioni

christiaan.jacobs@ext.jrc.ec.europa.eu

C. C. Koopmans

c.c.koopmans@vu.nl

1 Institute for Environment and Sustainability, Sustainability Assessment Unit, European Commission, Joint Research Centre, Via E. Fermi, 2749, 21027 Ispra, VA, Italy

2 Faculty of Economics and Business Administration, VU University Amsterdam, Boelelaan 1105, 1081 HV Amsterdam, The Netherlands 
JEL Classification H54 $\cdot$ L92 $\cdot \mathrm{O} 33 \cdot \mathrm{R} 42$

\section{Introduction}

The expansion of transport networks is considered an important factor for the spatial distribution of activities and receives considerable politic and academic attention. It is commonly perceived as a technology diffusion process in which the innovation spreads geographically (Grübler 1990; Nakicenovic 1995). The geographic paths that the developed networks assume have important societal and economic ramifications. Ideally these paths constitute a social optimum considering construction costs and generalized travel costs. However, due to often noncooperative decision-makers (Knick Harley 1982; Dobbin and Dowd 1997; Xie and Levinson 2011), potential transport network expansion outcomes may be limited to Nash equilibria (Bala and Goyal 2000; Anshelevich et al. 2003) that can entail considerable extra costs to reach a target state of connectivity.

Although it is known that transport network expansion may follow a clear rationale, largely based on, e.g. expected transport flows versus costs (Rietveld and Bruinsma 1998; Xie and Levinson 2011), relatively little is known about how economic and institutional conditions affect transport network expansion. This is partially because, in contrast to other instruments available to transport planners such as land-use and transport demand models, ex ante models of transport network expansion are few and they are hardly ever empirically validated. For a comprehensive overview of transport network modelling, we refer to Xie and Levinson (2009). In the 1960s, conceptual and empirical modelling efforts have been undertaken by quantitative geographers (Taaffe et al. 1963; Warntz 1966; Kolars and Malin 1970). More recently, network optimality and bi-level optimization methods (Patriksson 2008; Youn et al. 2008; Li et al. 2010), the role of selforganization (Xie and Levinson 2011) and the role of ownership (Xie and Levinson 2007) have been investigated in controlled conditions. This has been followed by empirically based exercises to test heuristic network design optimization methods (Vitins and Axhausen 2009), to understand the driving forces of network growth (Rietveld and Bruinsma 1998) and the role of first mover advantages (Levinson and Xie 2011) and to forecast future network investments in a fairly mature transport system (Levinson et al. 2012).

An instrument to evaluate geographically explicit network expansion outcomes in settings with multiple decision-makers is not yet available in the literature. This is presumably because of limited data availability, computational limitations and difficulties in reproducing topologically realistic links or 'shortcuts' (Li et al. 2010). The aim of this paper is to introduce transport link scanner (TLS), an agent-based model that simulates the overall geographic diffusion of a transport network through the individual investment decisions that drive network expansion, and to demonstrate that it is able to reproduce a historical network expansion process reasonably accurate. The model allows the inclusion of multiple decision-makers with varying objectives; institutional conditions and the level of cooperation between decisionmakers can be explicitly modelled. A novel heuristic method is integrated to generate 
the plausible geographic paths of potential investments that aim to maximize fares. It does so in a manner that is consistent with the model's transport demand module and is responsive to previously selected links. The principal model output is a network of transport links, which enables the measurement of model performance based on graph-theoretic indicators such as diameter and node degree (Rodrigue et al. 2006), and indicators relevant to transportation networks such as accessibility and network efficiency (Jacobs-Crisioni et al. 2016). The model is illustrated with a case study in which the start and expansion of the Dutch railway network in the nineteenth and early twentieth century is simulated, but the model itself is developed in such a way that other applications may be configured reasonably easily.

The theoretical basis, overall structure and key assumptions are outlined in Sect. 2. Subsequently, particular aspects of TLS are described in more detail in Sect. 3. The case study is described in Sect. 4, and simulation results for that case study are given in Sect. 5. This is followed by general conclusions on the development of TLS and ideas for further research in Sect. 6. Lastly, the estimation of cost and demand functions, a breakdown of model results per investor type and a table of nomenclature are given in appendices. Before the model and case study are introduced, it is worth mentioning that this model is programmed in the Geo Data and Model Server (GeoDMS) software (ObjectVision 2014), which is presumably best known as the platform that supports land-use models such as Land-Use Scanner and the Land-Usebased Integrated Sustainability Assessment modelling platform (LUISA) (Hilferink and Rietveld 1999; Baranzelli et al. 2014). GeoDMS is rather different from commonly used GIS packages, and we emphasize here that its availability has been a key prerequisite for the development of TLS. It is an open-source platform that interprets scripts into a sequence of operations and executes these operations on dynamically defined $\mathrm{C}++$ arrays. Just like geospatial semantic array programming tools such as the Mastrave library (de Rigo et al. 2013), GeoDMS adheres to largescale modelling and assessment tasks. The major advantages of using GeoDMS for the work presented in this paper are considerable gains in computation speed, reproducibility of modelling steps, flexibility and control over data operations and straightforward links between various data types such as raster and vector type spatial data. The TLS program and the data that have been used for this paper are freely available through http://www.jacobs-crisioni.nl/publications/download_tls.

\section{Model structure and key assumptions}

Transport network expansion is commonly initiated by a technical innovation that can substantially lower generalized travel costs, such as the introduction of steam power or the invention of motorways (Nakicenovic 1995). The expansion process itself is the result of sequential decisions to construct transport links for that new technology. Transport link investments generally come with considerable set-up costs and sunk costs and are physically bound, thus making it hard for investors to move their enterprise (Xie and Levinson 2011). The involved decision-makers may be private or public and may have very different objectives, including economic and societal factors, but are generally concerned with providing transport service for 
which the built infrastructure is instrumental. Because of the high costs of market access, in many cases the transport market is an oligopoly subject to fierce competition (Knick Harley 1982; Veenendaal 1995). Thus, potential final network outcomes consist of Nash equilibria rather than a social optimum (Anshelevich et al. 2003; Xie and Levinson 2007; Youn et al. 2008).

Given high costs of link construction, it stands to reason that investment decisions are taken with deliberation and that an investor will decide to construct the link that best fits investor objectives. The high costs involved in link construction create local monopolies when largely exhausted revenues block competitor investments in the same space (Xie and Levinson 2011). The position of the first investor is further boosted by the existence of network externalities that imply that newly added links may increase revenues for the existing network. This leads to advantages for the established playing field, as can be seen in the first mover advantages and lock-in described by network economics. For an overview of network economics, we refer to Economides (1996). All in all, sequential link construction is a dynamic process in which previous decisions organize the potential for future decisions. The characteristics of network expansion processes are the basis for the 'strongest link' assumption of transport network expansion (Xie and Levinson 2011), which is adopted in this paper. In such an approach, any agent selects a most attractive investment for construction, if a sufficiently attractive option is available. After that decision, investments are reconsidered and construction decisions are taken iteratively until the pool of sufficiently attractive investments is exhausted.

\subsection{Model structure}

Especially when network expansion is driven by economic motives, the spatial distribution of suitable terrain and potential transport revenues may be presumed to be important aspects of the choice process. This may be one reason why railways prefer paths with high potential interaction values (Warntz 1966; Kolars and Malin 1970). The geographic nature of these factors supports GIS-based modelling such as in TLS. In TLS network, investments are drawn from a pool of potential network extensions with plausible geographic paths. That selection of extensions is based on a set of adaptable rules. The modelled network investments are discrete choices. The model is turn-based and dynamic: thus, one investment decision from one investor is allocated in any iteration, causing one distinct link to be added to the modelled transport network. The transport link allocated in that iteration affects the market conditions that are relevant for the generated choice set and for the estimated revenues of investments in subsequent turns. The model allows multiple investors to construct network links, such as private investors or governments. The partaking investors are allowed differing investment objectives.

The model is comprised of four modules that are tasked with: (1) the preferences and the financial capacity of partaking investors; (2) the generation of a choice set; (3) the estimation of investment attractiveness; and (4) the selection of an investment. The model structure is outlined in Fig. 1. All elements of the model will be treated in the following sections. 


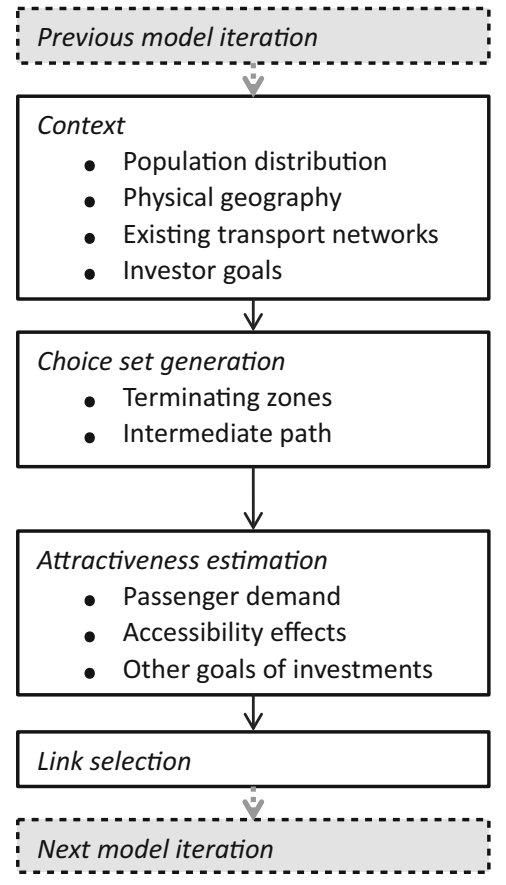

Module handling scenario settings

Module handling input data

Loads concurrent model state and

population distribution

Module for choice set generation Estimates changes in demand and evaluates optimal paths

Module for estimating trip

generation and network allocation

Module for aggregating operatorspecific demand effects, computing accessibility impacts, other goals

Module for link selection and storage

Fig. 1 Structure of one model iteration in TLS and the model's various modules. In each iteration, one investment, identified as a link between two zones, is allocated to the current transport network

\subsection{Key assumptions}

The investment decisions are assumed to be determined by repeatedly selecting the most attractive combination of investment and investor from a limited number of alternatives. The attractiveness of these options is governed by a conditional logit model (McFadden 1974), which is chosen because the multi-investor nature of TLS causes that variables differ for different investors. That condition excludes the mixed logit models used by, for example, Levinson and Karamalaputi (2003). Distinct choices are treated as separate trials, in which an observed addition to the railway network is chosen from a set $H$ of alternative-investor combinations. $H$ contains a finite number of alternative-investor combinations $O$ with index $l=1, \ldots, L$, and known attributes. This choice set is composed of a number of likely additions. Then, the probability that alternative $o$ is realized equals:

$$
P_{o}\left(S_{o} \mid O\right)=\frac{e^{S_{o}}}{\sum_{l=1}^{O} e^{S_{l}}},
$$

which is repeated for each choice situation.

It contains the estimated attractiveness function $S_{l}$ for a line $I$ given investor type $p$, which takes this form: 


$$
S_{l}=\beta_{0 p} \mathrm{ROI}_{l}+\beta_{n p} X_{n l}+R_{p}+R_{l}+\varepsilon,
$$

where $\mathrm{ROI}_{l}$ indicates the return on investment that investors presumably seek. This is modelled by the estimated increase in passenger mileage on an investor's network, divided by the estimated costs of building the link; $X_{n}$ is a vector of variables used to capture other factors that affect the attractiveness of investment options; $R_{p}$ and $R_{l}$ are alternative-specific and investor-specific random components that ensure that the model does not yield multiple alternatives with identical probabilities; and $\varepsilon$ is a random disturbance.

The attractiveness of alternatives may differ per investor and may contain a variety of different social or financial objectives. In the presented case study, investor-specific attractiveness functions have been estimated using railway investment choices taken while constructing the Dutch railway network and mainly aim at increasing the revenues (reflected by passenger kilometres) on the investor's network; in other cases, these attractiveness functions need to be modified to reflect case-specific investor goals or transport revenue types.

The selection of investment choices and the computation of investment attractiveness is constrained by the following assumptions: (1) the territory is divided into a given number of zones with estimable numbers of potential passengers and/or movable goods, observed as origins ( $i$ ) and destinations $(j)$; furthermore, (2) all zones are already connected by a preceding base communications network (base), so that spatial interactions already exist before the transport mode is introduced. This network is expected to have maximum plausible connectivity, so that the $i$ to $j$ travel distances $L_{i j}^{\text {base }}$ obtained from this network are the minimum realistic link lengths between two zones. A last constraining assumption (3) is that the introduced transport mode is expected to lower generalized travel costs per kilometre with a fixed relative cost improvement factor $\varphi$.

We must emphasize that the value of $\varphi$ has a considerable impact on results of the network allocation model. In this study, relative general cost improvements depend on the transport speeds on the base network ( $\left.V^{\text {base }}\right)$ and the transport speeds on the introduced network $\left(V^{\text {intr }}\right)$, so that $V^{\text {intr }} / V^{\text {base }}=\varphi$. One implication of the model's assumptions is that the links $l$ in the modelled network have travel costs $c$ based on $c_{l}^{\text {base }}=L_{l} / V^{\text {base }}$ or $c_{l}^{\text {intr }}=L_{l} / V^{\text {intr }}$, where $L_{l}$ indicate link lengths. In the case of public transport, it seems fair to adapt travel cost estimates with travel cost penalties $c p$ to simulate the effort involved in entering and exiting the introduced transport network. This leads to fixed maximum obtainable travel cost improvements between two zones, which can be computed as a ratio between minimum new-mode travel costs $c_{i j}^{\min }$ and existing travel costs $c_{i j}^{\text {base }}$ over the base network. Maximum obtainable travel cost improvements are expressed as:

$$
c_{i j}^{\text {base }} / c_{i j}^{\text {min }}=\left(L_{i j}^{\text {base }} / V^{\text {base }}\right) /\left[\left(L_{i j}^{\text {base }} / V^{\text {intr }}\right)+2 c p\right],
$$

in which maximum factor improvements are computed as base travel costs divided by minimum achievable travel costs. Those factors in turn are computed as network 
length divided by base transport mode speed, and minimum travel costs are computed as the time used to transverse the same network length using the introduced transport mode plus fixed travel cost penalties to enter and exit the introduced transport mode. Thus, travel costs improvements are assumed to have a fixed maximum, which has important ramifications for the selection of a choice set. This can be seen in the following sections.

\section{Choice set generation, investment selection and model accuracy measures}

Although in continuous space infinite potential links exist, computational limitations force us to work with a limited choice set. This is justified by the property of the conditional logit model demonstrated by McFadden (1974) that drawing a limited number of alternatives leads to consistent estimates, provided that the true choice process is described by the estimation procedure. ${ }^{1}$ TLS establishes a set of discrete choice set alternatives by drawing samples with a reasonable probability of selection using heuristic generation methods. In the attractiveness estimation procedure, the built links are added to the choice set. Because of the dynamic nature of TLS, the choice sets used in prediction are bound to differ from those used in the estimation process, and we must therefore assume that the validity of estimated attractiveness functions holds as long as investment options are selected with the same criteria as the choice set used in the estimations.

We furthermore assume that link construction is incremental, which implies that the most profitable link construction investments are selected first, and later, other links are built as extensions to the investor's network. To generate investment options given these assumptions, a two-stage method is applied, which first deals with the selection of terminating zones and later selects a plausible path between the terminating points using corridor location searching methods. For a recent overview of corridor location search methods, we refer to Scaparra et al. (2014). For this section, it is necessary to explicitly discern links $(l)$, which we consider as complete investments between two terminating zones, and segments $(s)$, which are the separately observed lines in the model of which a link is composed.

\subsection{Selecting terminating zones}

The investment options are picked from a subset of zone pairs with high revenues compared to costs. We compute a first estimate of the relative revenue-to-cost ratio (RCR) of a potential new link by dividing additional passenger kilometres by construction costs $\mathrm{C}$ :

\footnotetext{
1 An assumption of multinomial logit models is independence of irrelevant alternatives. There have been some recent attempts to develop sampling strategies that may overcome this assumption; see, for example, Guevara and Ben-Akiva (2013). However, it is beyond the scope of the present paper to try and apply such methods, in particular since the generation of meaningful links is not trivial, as can be seen in the rest of the paper.
} 


$$
\mathrm{RCR}_{i j}^{\mathrm{est} 1}=L_{i j}^{\mathrm{base}}\left(T_{i j}^{\mathrm{est} 1}+T_{j i}^{\mathrm{est} 1}-T_{i j}^{\mathrm{curr}}-T_{j i}^{\mathrm{curr}}\right) / C_{i j}^{\mathrm{est} 1},
$$

where $L_{i j}^{\text {base }}$ is a first estimate of link length defined as the shortest distance between $i$ and $j$ in kilometres over the base network; $T$ is the potential number of trips in both directions with (est1) and without (curr) the new link; and $C_{i j}^{\text {est1 }}$ is a first estimate of construction costs.

Lengths and costs are assumed to be symmetric for both directions. We must emphasize here that the link lengths and flows for potential investments are rough estimates, because at this step in the selection procedure the optimal path of a potential link between $i$ and $j$ is not yet known and as a consequence, neither are the definitive travel times. The construction costs are obtained by finding the least-cost path between zones given estimated construction costs for each potential network segment. These construction costs are imposed on a fine-meshed network of regularly distributed segments, which is elaborated upon later.

Potential trips $T$ between zones are computed using a spatial interaction model derived from Alonso's General Theory of Movements (GTM) (Alonso 1978). It must be emphasized that in the model these formulations can be easily substituted by any other spatial interaction formulation, for example to take into account spatial dependencies (Patuelli and Arbia 2013), heterogeneity or endogeneity (Donaghy 2010). For the selection of terminating zones, we compute trips $T$ in three cases:

$$
\begin{array}{cl}
T_{i j}^{\text {base }}=\left(A_{i}^{\text {base }(1-\gamma)}\right)^{-1} P_{i} P_{j} f\left(c_{i j}^{\text {base }}\right), & \text { and } A_{i}^{\text {base }}=\sum_{j} B_{j}^{1-\theta} P_{j} f\left(c_{i j}^{\text {base }}\right) ; \\
T_{i j}^{\text {curr }}=\left(A_{i}^{\text {curr }(1-\gamma)}\right)^{-1} P_{i} P_{j} f\left(c_{i j}^{\text {curr }}\right), & \text { and } A_{i}^{\text {curr }}=\sum_{j} B_{j}^{1-\theta} P_{j} f\left(c_{i j}^{\text {curr }}\right) ; \\
T_{i j}^{\text {est } 1}=\left(A_{i}^{\text {est } 1(1-\gamma)}\right)^{-1} P_{i} P_{j} f\left(c_{i j}^{\text {est } 1}\right), & \text { and } A_{i}^{\text {est } 1}=\sum_{j} B_{j}^{1-\theta} P_{j} f\left(c_{i j}^{\text {est } 1}\right) ;
\end{array}
$$

where $P$ represents zonal populations; $c_{i j}^{\text {base }}$ describes travel costs over the base network; $c_{i j}^{\text {curr }}$ describes current travel costs obtained from the network at the start of

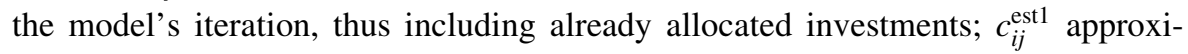
mates travel costs if the potential investment is in place and is computed as $c_{i j}^{\text {est1 }}=L_{i j}^{\text {base }} / V^{\text {intr }} ; f($.$) is a distance-decay function; \gamma$ and $\theta$ are parameters that govern transport consumption elasticity for reduced travel costs; and $B_{j}$ is a destination-specific constant that may be used to model congestion at destinations.

The computed levels of $\mathrm{RCR}_{i j}^{\text {estl }}$ are instrumental to select a pool of potentially high revenue-to-cost ratio investments from which investment options in $O$ are selected. To exclude lines that offer relatively small total travel cost improvements between two terminating zones, the line proposed in $c_{i j}^{\text {estl }}$ must offer minimally half the maximum travel cost improvements that may be obtained by substituting a base network link with the link considered. Furthermore, intrazonal links and 
symmetrical elements in the matrix are excluded. These criteria yield the following selection dummy $Z_{i j}$ :

$$
Z_{i j}= \begin{cases}1 & \text { if }\left(c_{i j}^{\text {est } 1} / c_{i j}^{\text {curr }}\right) \geq 0.5\left(c_{i j}^{\text {est } 1} / c_{i j}^{\text {base }}\right) \quad \text { and } i<j . \\ 0 & \text { otherwise }\end{cases}
$$

The criterion is admittedly chosen ad hoc, but seems to be a reasonable assumption. This selection criterion is necessary to obtain a small choice set with reasonably plausible alternatives. Note that in the case that $c p>0$, proposed links between $i$ and $j$ also have an absolute minimum distance, because with lower distances the rail link's travel cost including waiting times does not offer sufficient travel cost advantages. Finally, a fixed number of links between $i$ and $j$ with the highest values of $\mathrm{RCR}_{i j}^{\text {estl }} Z_{i j}$ are selected as investment options.

\subsection{Finding plausible paths}

Simply connecting two zones without detours leads to the odd situation that the link does not serve the zones that it passes. Optimal transport lines may 'depart from the straight line' when a detour improves the balance between revenues and construction costs (Morrill 1970). The links between selected terminating zone pairs are therefore allowed to detour. Three factors are taken into account in the path selection mechanism, namely potential revenues, construction costs and the overall length of the link. These are used to obtain optimal paths given revenue-to-cost ratios based on differently weighted combinations of the three factors. In all cases, optimal paths are searched that meet a minimum travel cost improvement. Thus, the maximum length of a link $L_{i j}^{\text {intrmax }}$ is a logical consequence of the maximum travel cost improvements in (3), $\varphi$, and the criterion used in Eq. (6), and is defined as:

$$
L_{i j}^{\text {intr max }}=V^{\text {intr }}\left[\left(c_{i j}^{\text {base }}-2 c p\right) / 0.5(\varphi)\right],
$$

so that to achieve the maximum link distance, the maximum acceptable travel costs are multiplied with the speed of the introduced transport model. To obtain optimal paths, the continuous space in which built lines are determined is approximated by a regularly formed network of potential line segments, in which equally distributed nodes connect the nearest nodes in a set number of directions (see Fig. 2). This is a common approach in corridor location problems (Goodchild 1977; Scaparra et al. 2014). The spatial resolution of this network is $1 \mathrm{~km} \times 1 \mathrm{~km} \times 32$ directions so that network density $r=4$. The used method differs somewhat from known solutions to corridor location problems. The key difference is that the used method depends on the outcomes of previous model iterations and may yield different results in subsequent model iterations. To allow for this, the regularly latticed network is combined with the network already built at the start of the model's iteration and with segments that connect the simulated rail network to zone centroids. The combined network and a shortest path finding algorithm are used to 


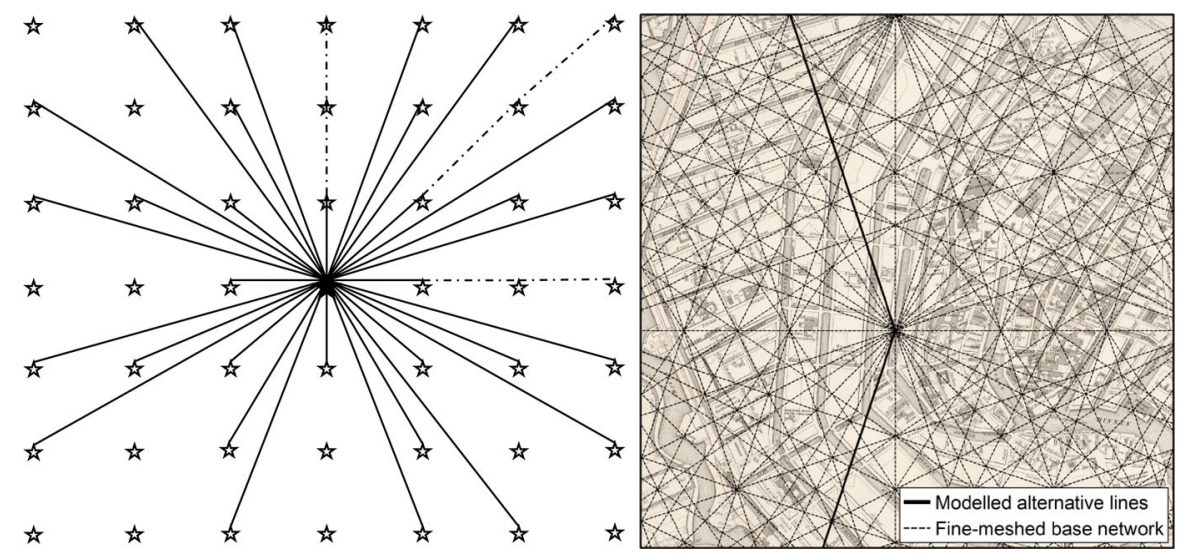

Fig. 2 Schematic example of a regularly formed network with equally dispersed nodes shown as stars, segments from the centre node shown as regular lines and exemplary additional segments shown as dashed lines (left); example of the regularly formed network shown as dashed lines and potentially derived link shown as regular bold line positioned over a map of Amsterdam in 1842 (right)

obtain a path with an optimal combination of revenues, construction costs and length.

The revenue-cost indicators per segment $s$ are computed as:

$$
\mathrm{RC}_{s}=\left(R_{s} / C_{s}\right)^{1-k} / L_{s},
$$

where $R_{s}$ indicates estimated revenues obtained from the segment; $C_{s}$ indicates costs of segment construction; and $L_{S}$ indicates segment lengths. This formula puts a high weight on the revenue-to-cost ratio for low values of $k$, while the least lengthy path is favoured in case $k=1$. The method to estimate segment revenues will be explained later. Construction costs are obtained from terrain characteristics. To model additive network construction, already built railway segments are given a very low cost of one. Note that more sophisticated cost structures for existing links can be configured to simulate specific cooperation conditions. Finally, segment lengths are primarily taken into account to ensure that the found path respects $L_{i j}^{\text {intr }}<L_{i j}^{\text {intr max }}$.

The inverse $\mathrm{RC}_{S}^{-1}$ is used as a measure of friction for each segment. Subsequently, Dijkstra's least-friction path algorithm is applied to find a path between the terminating zones with the lowest total friction. Clearly, this approach provides the possibility to obtain optimal paths according to a limited set of parameterized factors. Because methods to obtain real parameter values for path selection are not yet available, we iterate the importance of segment revenue-to-cost ratios using the $k$ parameter. Thus, the shortest path finding algorithm with $\mathrm{RC}_{S}^{-1}$ is repeated in 40 iterations, in which $k$ is gradually increased from zero to one. The total inverse revenue-cost indicator of a path is: 


$$
\mathrm{RC}_{\mathrm{TOT}}^{-1}=\sum_{s=1}^{n} \mathrm{RC}_{S}^{-1}=\sum_{s=1}^{n} L_{s} /\left(C_{s} / R_{s}\right)^{1-k}
$$

For $k=0$, this amounts to a distance-weighted sum of inverse revenue-to-cost ratios, while for $k=1$ it is simply total distance.

\subsubsection{Estimating segment revenues}

The revenues for each segment are estimated using a relatively straightforward method. Explicitly taking into account revenues with different railroad line geometries might require repetitive re-estimation of transport demand with various path alternatives, which is computationally infeasible. We therefore take the potential fare of a link as a proxy for potential revenues. This can be partially done by taking into account the amount of people in the zones that a link connects. To take into account that zones which are already connected to the network might suffer from transport market saturation, we also include MS, which approximates transportation market saturation at the origin and destination, so that:

$$
\mathrm{MS}_{i}=\sum_{j=1}^{n} \frac{\left(\left[L_{i j}^{\mathrm{base}} T_{i j}^{\mathrm{est} 1}-L_{i j}^{\mathrm{base}} T_{i j}^{\mathrm{base}}\right]-\left[L_{i j}^{\mathrm{base}} T_{i j}^{\mathrm{curr}}-L_{i j}^{\mathrm{base}} T_{i j}^{\mathrm{base}}\right]\right)}{\left(\left[L_{i j}^{\mathrm{base}} T_{i j}^{\mathrm{est} 1}-L_{i j}^{\mathrm{base}} T_{i j}^{\mathrm{base}}\right]\right)},
$$

in which the relative amount of passenger kilometres that can be obtained by connecting a zone is estimated, given a base level of passenger kilometres $\left(L_{i j}^{\text {base }} T_{i j}^{\text {base }}\right)$, the current level of passenger kilometres $\left(L_{i j}^{\text {base }} T_{i j}^{\text {curr }}\right)$ and the presumed maximum number of passenger kilometres $\left(L_{i j}^{\text {base }} T_{i j}^{\text {est1 }}\right)$. $\mathrm{MS}_{i}$ is zero if the market is fully saturated and one if there is no saturation whatever. Finally, the segments' revenue levels are estimated as average non-saturated potential revenues in the zones in which both the first and the last point of a segment are located:

$$
R_{s}=\frac{1}{2}\left[\sum_{i=1}^{n} \operatorname{MS}_{i}\left(P_{i s 1}+1\right)+\sum_{i=1}^{n} \operatorname{MS}_{i}\left(P_{i s 2}+1\right)\right],
$$

where revenues $R$ of segments $s$ are computed by means of the population $P$ of zone $i$ in which the segment's first point $(s 1)$ and last point $(s 2)$ are located and the zone's saturation factor $\mathrm{MS}_{i}$. One person is added to each zone to ensure that values of $R_{s}$ are above zero and thus warrant the computation of Eq. (9).

\subsubsection{Optimal path selection}

The iterative path finding method leaves 40 alternative paths with varying lengths. These varying lengths signify a varying mix of revenue-cost optimization and length reduction. We must acknowledge that in some cases the method captures many alternatives with similar geometries, thus causing inefficiencies in the alternative path generation. An extension of the model using recent advances in corridor 
location problems such as those proposed by Scaparra et al. (2014) may be explored in the future to solve this. To find the likely most profitable path, the passenger kilometre increases obtained are recomputed for the whole $i$ to $j$ matrix, for which the travel costs and travel distances between connected zones are repeatedly reestimated for every value of $k$. To do so, a dummy variable $Q_{i}$ indicates whether zone $i$ is connected to the alternative path at hand. Subsequently, the estimated travel $\operatorname{costs} c_{i j}^{\text {curr }}$ and travel distances $L_{i j}^{\text {base }}$ between all connected zones are updated so that $c_{i j}^{\text {est } k}$ and $L_{i j}^{\text {est } k}$ are defined for each alternative path $k$ as:

$$
\begin{gathered}
c_{i j}^{\text {est } k}= \begin{cases}\text { path travel costs } & \text { if } Q_{i} Q_{j}=1 \\
c_{i j}^{\text {curr }} & \text { otherwise }\end{cases} \\
L_{i j}^{\text {estk }}= \begin{cases}\text { path travel distance } & \text { if } Q_{i} Q_{j}=1 \\
L_{i j}^{\text {base }} & \text { otherwise }\end{cases}
\end{gathered}
$$

which enables a more accurate estimate of revenues within the scope of the connected zones. $L_{i j}^{\text {base }}$ is used in (13) because a shortest length finding method on the current network would always represent the geographically more efficient base network, regardless of the state of the introduced transport mode. As with the first estimate, revenues from not directly connected zones are neglected here. This is a necessary evil to prevent excessive computational requirements in this stage of the modelling exercise. Furthermore, the sum of segment construction costs is taken so that the overall cost of the path for the iteration is known as $C^{\text {est } k}$. These new cost and revenue estimates are used to estimate path revenue-cost indicators using:

$$
T_{i j}^{\mathrm{est} k}=\left(A_{i}^{\mathrm{est} k(1-\gamma)}\right)^{-1} P_{i} P_{j} f\left(c_{i j}^{\mathrm{est} k}\right), \quad \text { and } A_{i}^{\mathrm{est} k}=\sum_{j=1}^{n} B_{j}^{1-\theta} P_{j} f\left(c_{i j}^{\mathrm{est} k}\right) .
$$

Finally, the overall length of the link is computed as $L^{\text {intr } k}$ and used to obtain the final revenue-cost ratios of all paths, so that:

$$
\mathrm{RCR}^{\text {est } k}= \begin{cases}\sum_{i=1}^{n} \sum_{j=1}^{n}\left[L_{i j}^{\text {est } k}\left(T_{i j}^{\text {est } k}\right)\right] / C^{\text {est } k} & \text { if } L^{\text {intr } k}<L_{i j}^{\text {intr max }} \\ \left(L^{\text {intr } k}\right)^{-2} & \text { otherwise }\end{cases}
$$

In Eq. (15), the length of links is purposely squared to enforce that the shortest path is only selected if no path is found that meets the $L_{i j}^{\text {intrmax }}$ criterion. Subsequently, the path with the highest value of RCR is selected. In this way, the path with the highest estimated revenue-to-cost ratios is selected if a path that meets the length criterion is found, and else the method picks the path with the shortest overall length.

It is important to note that two additional restrictions are imposed on the path decision method: first, we assume that railway network construction is incremental, so that a) in all cases, if a link starts or terminates in a zone already connected by a built line, the generated line must connect to the line already built there and $b$ ) the 
links of an investor's already existing network have negligible costs for the considered expansion; second, to simulate that built railway links terminated outside contemporary urban areas, the link may not start on a node less than 500 metres away from the zone's centroid. This approximates the distance between stations and urban area centres that are observable in the historically built network.

\subsection{Investment selection}

Subsequently, the attractiveness of the investment options is computed. A wide range of variables that deal with investor objectives can be computed here. Increasing mileage, total transport flows or reduction in congestion due to insufficient transport network capacity are, presumably, generally important reasons for transport network investments. TLS therefore includes a module to model expected transport flows on potential network extensions, on the investor's remaining network or on the whole transport network.

For all investment options generated in the choice set, the attractiveness is estimated with the methods shown in the previous section, yielding values of $S_{l}$ specific for each investor in a vector that is as long as the number of active investors times the number of options. A very small random component is added to the computed attractiveness values to warrant that two options do not have identical attractiveness. Based on the estimated values, Eq. (1) is solved to obtain probabilities for the considered investments. Ultimately, the investment with the highest probability is selected. The new link and its relevant attributes are added to the already existing network in a new file; this file may form the basis for the evaluation of a subsequent investment if need be.

\subsection{Measuring model accuracy}

The primary goal of this paper is to demonstrate that modelling transport network development with reasonable geographic accuracy is feasible. Xie and Levinson (2011) use rank correlations to verify to what degree their model captures the sequence of links accurately. Unfortunately this only works if the modelling is restricted to the topology of the observed network, which is not the case in TLS. A visual inspection of allocation results yields useful insights, but does not provide the possibility to assess the accuracy of the model at hand in a balanced and objective manner, for which accuracy indicators and a baseline comparison are necessary. Although many network-based indicators to compare modelling results are conceivable such as the ones provided by Rodrigue et al. (2006), we concentrate on two indicators that deal with geographically relevant aspects of the results. One indicator measures to what degree the same zones are connected as have been connected by the historically built line; and the other indicator measures differences in travel times. Because we assume that model accuracy is more critical for populous areas, all indicators are weighted by population. Weighted connection error WCE is thus measured as: 


$$
\mathrm{WCE}=1-\left(\sum_{i=1}^{n}\left(P_{i}^{\mathrm{observed}} X_{i}^{\text {modelled }} X_{i}^{\mathrm{observed}}\right) / \sum_{i=1}^{n} P_{i}^{\text {observed }} X_{i}^{\text {observed }}\right),
$$

where $X$ is a zone-specific dummy that takes the value one when a municipality is connected by the modelled and observed railway networks, and zero otherwise.

Essentially this measure indicates to which degree the zones that were connected by the really built network are being connected by the modelled network, and it thus only measures double positives. We believe this is sufficient for the scope of this paper but plan to develop a wider range of indicators in further exercises. The weighted mean average absolute percentage travel-time error ('WMAPE') is measured as:

$$
\text { WMAPE }=\frac{1}{n} \sum_{i=1}^{n} \sum_{j=1}^{n}\left(\frac{P_{i}^{\text {observed }} \mathrm{Abs}\left[c_{i j}^{\text {observed }}-c_{i j}^{\text {modelled }}\right]}{P_{i}^{\text {observed }} c_{i j}^{\text {observed }}}\right),
$$

where the absolute population-weighted differences between the observed and modelled travel times are expressed as percentage of the observed travel times, and the final results are subsequently averaged. Naturally, in both the modelled and historical networks the same rules regarding waiting times and travel speeds are upheld to enable a fair comparison of travel times.

To ensure a meaningful comparison, modelled networks are compared with the state of the historically built network that is closest to the modelled network in terms of length. Thus, if in the fourth investment turn, a modelled network has a length of $1000 \mathrm{~km}$, subsequent individual historical investments are tested for cumulative length until the historical investment is selected that brought the historically built network the closest to a 1000-km cumulative length. The network comprising that and previous investments is selected for comparison. In addition, the population levels of the year in which the selected historical investment is built are selected to serve as weights for the presented indicators.

\section{Case study}

In this section, we present an effort to simulate the development of the Dutch railway network in the nineteenth and early twentieth century using TLS. Investment attractiveness functions were fitted on observed transport network investments. First the history of the development of that railway network is summarized, after which the model set-up, main assumptions and estimation of transport link attractiveness are outlined.

\subsection{The development of the Dutch railway network}

The first railway in the Netherlands opened in 1839 (Veenendaal 2008). It was operated by the 'Holland Iron Railway Company' (HSM) and linked Amsterdam to Haarlem. It was soon extended towards Rotterdam. Subsequently, competing 


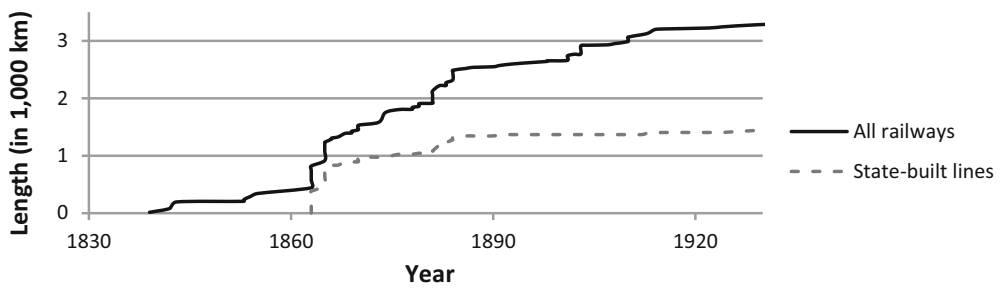

Fig. 3 Length of railway lines in the Netherlands over time

companies built their own lines in the Netherlands. More than ten operators have separately provided railway services on railway links in the Netherlands. The Dutch government began participating actively by building state lines defined in the Railway Acts of 1860 and 1875. Most of those state lines were run by the 'State Railways' (SR), a private company which leased lines owned by the state. In 1878, a third Act followed that allowed for the cheaper construction of railways, if operated with slow light trains. Supported by attractive loans from the Dutch State and subsidies from local governments (Doedens and Mulder 1989), this Railway Act incited the construction of 'local tracks' that typically connected rural areas to the main railway network (Veenendaal 2008) and were often subsidized by local governments. In this paper, we treat state involvement as the introduction of other types of investors with distinct preferences in the railway development playing field.

After an initial slow start, railway development began to pick up speed in the 1850s when additional operators and the Dutch state began to participate in network development (see Fig. 3). In total, 25 operators have operated rail lines in the country according to the data observed in this study. Increasing competition led to considerable growth in the length of the railway network between 1860 and 1890 . Many operators could not keep up, and in 1890 the infrastructure of the third largest railway operator ('NRS') was nationalized. After this, the railway transport market was almost completely in hands of HSM and SR. In 1917, decreasing revenues forced HSM and SR to cooperate within an institutional framework in which Dutch policies regarding railroad operations shifted from pro-competition to pro-cartel. Finally, in 1936 all railway infrastructure was nationalized, and operations were continued by the state. By 1936, opportunities for further railway network expansion evidently were exhausted and the network did not expand any further until the 1980s.

\subsection{Population distribution, network speeds and network ownership}

Based on Veenendaal (2008) and Stationsweb (2009), the historical railway network development in the Netherlands has been reconstructed in a GIS database that also contains population counts from 1830 to 1930 in 1076 municipalities. The data, furthermore, build on the same assumptions as in Koopmans et al. (2012), of which we now list the most important ones. The study area is assumed to already have an underlying network of paths that connects all municipalities with each other. In the 
nineteenth century, horse-drawn boats through the country's tow canals were the main long distance travel mode and often the only alternative to walking to most people. They operated at a speed that was but slightly faster than walking. We must acknowledge that the historical networks of paved roads and tow canals are not taken into account explicitly; instead, just as Koopmans et al. (2012), we consider both networks to be regional substitutes for each other that are approximated using one simplified network. In the case study, that network connects each municipality with its five nearest neighbours. A speed $V^{\text {base }}=6 \mathrm{~km} / \mathrm{h}$ is maintained as the average speed to traverse this network to proxy movement over roads and waterways. We assume this is a reasonably accurate assumption for the Netherlands. One model variant is run with $V^{\text {base }}=4 \mathrm{~km} / \mathrm{h}$ to test model sensitivity for this setting.

Municipalities are represented by means of their geographic centres. The base network has direct connections between those centroids. The rail network is connected to those centroids through connector road links. Train schedules or the accelerating and decelerating of trains are not explicitly modelled, but are approximated by imposing relatively low average speeds for the introduced transport links. To proxy that passengers lose some time with entering and exiting the rail network as well as with transferring between physically separate rail networks, a relatively small travel cost penalty $\mathrm{cp}=10 \mathrm{~min}$ is given to all connectors between rail networks and municipalities.

When assessing the attractiveness of investments, links of the previously modelled network extensions are included as well as the underlying network. As given in Sect. 4.3, passenger transport demand is an important reason for investment. The level of demand depends on generalized transport cost, which is proxied by travel time, and on price elasticity. This makes the modelled speeds on the railway network and assumptions on price elasticity a key factor for network outcomes. To take these factors into account, we present scenarios with varying travel-time improvements and with varying assumptions on price elasticity of passenger transport demand. Construction costs, passenger demand and price elasticity have been estimated using observed data. Details of the method used, data and results can be found in Appendices 1 and 2.

To model railway network expansion in a case with multiple investors with varying objectives, five independent investors are simulated. This set of investors consists of two regular private investors, two private local line investors and the state and roughly resembles the playing field during Dutch railway construction. The regular private investors partake in investments from the model start. The state partakes from 1860; local line investors from 1879. At any point, the investmentinvestor combination with the highest probability is selected. All investors are eligible to the same investments with attributes that may differ per investor; ten investment options are available in every round. The built lines are assumed to be operated by the building investor, so that all revenues from an investor's line are therefore assumed to fall to that investor. In the presented case study, the modelled investment sequence starts in 1839, with one investment allowed every year. After an investment, an operator is excluded one round to simulate financial recuperation 
and evaluation of the investment. Municipal population counts are updated every decade. If the model does not find any suitable investments, it skips years to a following decade; if it does no longer find suitable investments in 1930, the network expansion sequence ends.

Because both travel speed improvements and price elasticity can only be roughly estimated, we present a range of scenarios in which those assumptions vary considerably. In one scenario, train speeds are three times faster than the pedestrian network, so that average speed of train trips is defined as $V^{\text {intr }}=18 \mathrm{~km} / \mathrm{h}$ and $V^{\text {base }}=6 \mathrm{~km} / \mathrm{h}$, and total municipal transport consumption is affected by changes in travel times (scenario A). The level of elasticity is given as $\gamma$ as in Eq. (5a). In scenario $\mathrm{C}$, trains speeds are 7.5 times faster than the pedestrian network, with $V^{\text {intr }}=30 \mathrm{~km} / \mathrm{h}$ and $V^{\text {base }}=4 \mathrm{~km} / \mathrm{h}$, while municipal transport consumption is inelastic (scenario C). In four other scenarios, train speeds are five times faster, with $V^{\text {intr }}=30 \mathrm{~km} / \mathrm{h}$ and $V^{\text {base }}=6 \mathrm{~km} / \mathrm{h}$, while municipal transport consumption is again inelastic (scenarios B1 to B4). In scenario B1, only train speed and transport consumption are changed. To understand the sensitivity of the model for other model assumptions, further variations in rules are simulated in scenarios B2 to B4. In scenario B2, investors are not excluded in the round directly following an investment. In scenarios B3 and B4, only regular private investors are modelled, so that state lines and local line investors are excluded in the simulations. In scenario B3, investors are assumed to be competitors, while in scenario B4, investors are assumed to be co-dependent. Co-dependency is approximated by adding the relative change in passenger mileage on the competitor network to the attractiveness function of an investment. All used scenarios are summarized in Table 1. We must acknowledge that this is not a complete sensitivity analysis in which all assumptions are varied independently. That is an almost impossible task, given the number of assumptions in the model and the minimum 10 days needed for one model run even

Table 1 The scenarios used

\begin{tabular}{llrl}
\hline Scenario & Description & $\begin{array}{l}\varphi \text { and } \\
\left(V^{\text {intr }} / V^{\text {base }}\right)\end{array}$ & $\gamma$ \\
\hline A & Slow trains, elastic consumption & $3(18 / 6)$ & 0.3 \\
B1 & Fast trains, inelastic consumption & $5(30 / 6)$ & 0 \\
B2 & As B1, but investors are not excluded directly after an investment & $5(30 / 6)$ & 0 \\
B3 & As B1, but only private investors & $5(30 / 6)$ & 0 \\
B4 & As B3, but change in passenger mileage on competitor network is a & $5(30 / 6)$ & 0 \\
& factor for investment attractiveness & $7.5(30 / 4)$ & 0 \\
C & Slower walking speeds, B5 parameters & $5(30 / 6)$ & 0 \\
Rietveld and & Reproduction of Rietveld and Bruinsma (1998) & & \\
\multicolumn{1}{c}{ Bruinsma } & & & \\
\hline
\end{tabular}

Parameter $\varphi$ indicates relative speed improvement as a ratio of the speed of the introduced transport mode $V^{\text {intr }}$ versus the speed of prior transport modes $V^{\text {base; }}$ see Sect. 2.2. Parameter $\gamma$ indicates transport consumption elasticity, see Eqs. (5a)-(5c) 
on a, at the time of writing, high-end $2.6 \mathrm{Ghz}$ Xeon PC. In any case, such a sensitivity analysis is outside of the scope of this paper. For future applications, we propose to pinpoint parameters that are crucial to conclusion validity and test model sensitivity for these parameters.

Measuring performance is meaningless without a baseline comparison of accuracy. To compare relative model performance, the model described by Rietveld and Bruinsma (1998) has been approximated using the TLS framework. The Rietveld and Bruinsma method repeatedly adds a straight line between the two cities that yield the highest expected return on investment. Only the 35 most populous cities in the country are taken into account. Costs are equal to length, with the exception of links that cross large waterbodies; those links cost a factor 20 more. No fixed costs or minimum travel times are applied, and varying investor differences are not accounted for. This model is implemented in TLS by selecting the highest value of Eq. (4), taking into account only the original subset of 35 cities. One link is added in every model iteration. All links are assumed to be private lines. The plausible paths method in Sect. 3.2 is adapted to exclude variation in estimated link revenues. The allocation procedure is finished when the pool of available cities is exhausted. We must note that a comparison with a socially optimal network (Li et al. 2010) is also useful here; further work is needed to establish norms for optimality and generate a meaningful optimum.

\subsection{Investment choices}

Because inland water transport provided the Dutch freight sector, a cheap substitute for rail passenger transport was a particularly important service for Dutch railway investors (Filarski and Mom 2008). Furthermore, railways have been considered to possess unifying qualities (Veenendaal 2008), which were presumably sought after by the Dutch administration in the nineteenth century. Although the 'United Provinces' created in the seventeenth century had become a centrally led monarchy by 1806 , the country was only starting to form a political union when the railways began to develop (Kossmann 1986).

To investigate the motives of investment decisions in the development of the Dutch railway network, the conditional logit choice model in (1) has been fitted on sets of built and unbuilt railway links. Investments were separated into regular private lines, private lines that comply with local track legislation, and state lines. As noted before, return on investment is assumed to be the key driving force. Revenues are expected to be linear with travelled distances; this cannot be validated because data on historical ticket pricing structures are currently unavailable. We thus implicitly assume that pricing levels were equal throughout the country regardless of regulation or level of competition. This is presumably not true, and the consequences are worth exploring in follow-up research.

Next to return on investment a number of other variables are taken into account in the attractiveness function. Amongst those, changes in the level of inequality of accessibility values proxy the endeavour of in particular government investors to reduce national disparities in economic opportunity. It is computed as changes in the Theil index of municipal accessibility levels. This variable takes this form: 


$$
\begin{gathered}
\mathrm{IA}_{l}=100\left[\frac{1}{n} \sum_{i=1}\left(\frac{A_{i}^{\mathrm{opt} l}}{\overline{A^{\mathrm{opt} l}}} \cdot \ln \frac{A_{i}^{\mathrm{opt} l}}{\overline{A^{\mathrm{opt}} l}}\right)-\frac{1}{n} \sum_{i=1}\left(\frac{A_{i}^{\mathrm{curr}}}{\overline{A^{\mathrm{curr}}}} \cdot \ln \frac{A_{i}^{\mathrm{curr}}}{\overline{A^{\mathrm{curr}}}}\right)\right], \\
A_{i}^{\mathrm{curr}}=\sum_{i \neq j} P_{j} f\left(c_{i j}^{\mathrm{curr}}\right) ; \quad A_{i}^{\mathrm{opt} l}=\sum_{i \neq j} P_{j} f\left(c_{i j}^{\mathrm{opt} l}\right),
\end{gathered}
$$

so that differences in the distributions of current accessibility levels $A_{i}^{\text {curr }}$ and accessibility levels $A_{i}^{\text {opt } l}$, which include the investment option $l$, are taken into account. Thus, $A_{i}^{\text {curr }}$ is a measure of accessibility with initial travel times; $A_{i}^{\text {opt } l}$ describes accessibility levels when including the travel costs improvements from the potential investment.

Furthermore, two dichotomous variables indicate whether a link connects to other links in the entire railway network and in particular to links on the operator's network. Connecting to the existing rail network is presumed to add option values for revenues of later connections to further cities; operational cost reductions for an operator because inventory can be kept at one centralized point; and furthermore, operators might consider that having an extensive connected network brings prestige. Another dichotomous variable indicates whether a link provides a first connection to provincial capitals or to the country capital city, Amsterdam. Connecting to these cities might be attractive if investors expected larger growth of the passenger market in those cities and might have prestige value as well. Yet another dichotomous variable indicates whether a link connects municipalities on the country border. This variable represents attempts to profit from international passenger and mail transport. A last dichotomous variable indicates whether a link connects to a sea harbour. This variable represents endeavours to connect Dutch sea harbours with their hinterlands by means of rail for the sake of goods transport.

The built links in the choice set were derived from the database of constructed railway links. We have used the following definition of a link: a link connects at least two existing nodes (railway junctions, stations or municipalities) and has been realized by an investor as one integrated project within a limited number of years. We assume that the results of the applied models are more accurate in the case of longer links, and therefore weight the results of Eq. (1) by the length of built link $o$, normalized by the average length of all built links in period $t$ so that the total number of observations in the choice model is not affected. To generate a choice set of unbuilt links, we applied the following procedure: (1) a set of 50 alternatives was generated for all links that were built in one decade; (2) to simulate that investors presumably had limited capital in particular in the early stages of network development, the costs of railway construction of an alternative could not exceed the costs of a built railway in a longer period (either 1839-1859, 1859-1889 or 1889-1929); (3) selection of terminating municipalities and the routing of the intermediate path were not affected by the transport market saturation of municipalities $M S$.

Going through the results in Table 2, one finds that private line investors were focused on high return on investments, while, compared with other alternatives with reasonably good return on investments, local line and state investments were rather 
Table 2 Results of fitting a conditional logit model on the attributes of the built and automatically generated unbuilt lines in the Dutch railway network

\begin{tabular}{|c|c|c|c|c|}
\hline \multirow[t]{2}{*}{ Scenario } & \multicolumn{2}{|l|}{ A } & \multicolumn{2}{|l|}{ B1 } \\
\hline & Coefficient & $Z$ score & Coefficient & $Z$ score \\
\hline \multicolumn{5}{|l|}{ Return on investment } \\
\hline Private lines & $0.64 * *$ & $(3.84)$ & $1.28 * *$ & $(3.81)$ \\
\hline Private local lines & 0.11 & $(0.58)$ & 0.38 & $(0.79)$ \\
\hline State lines & 0.46 & $(1.64)$ & 0.40 & $(0.81)$ \\
\hline \multicolumn{5}{|c|}{ Change in accessibility inequality } \\
\hline Private lines & $6.59 * *$ & $(3.03)$ & $8.16^{* *}$ & $(3.10)$ \\
\hline Private local lines & $-21.00 * *$ & $(-3.83)$ & $-20.53 * *$ & $(-3.70)$ \\
\hline State lines & $-20.89 * *$ & $(-4.48)$ & $-23.20 * *$ & $(-5.10)$ \\
\hline \multicolumn{5}{|l|}{ Connects operator network } \\
\hline Private lines & 1.69 & $(1.76)$ & 1.69 & (1.78) \\
\hline Private local lines & $2.42 * *$ & $(3.11)$ & $2.22 * *$ & $(2.87)$ \\
\hline State lines & $3.83 *$ & $(2.57)$ & $4.07 * *$ & $(2.76)$ \\
\hline \multicolumn{5}{|l|}{ Connects railway network } \\
\hline Private lines & -0.65 & $(-1.05)$ & -0.71 & $(-1.17)$ \\
\hline Private local lines & 0.05 & $(0.12)$ & 0.14 & $(0.31)$ \\
\hline State lines & $-2.68 * *$ & $(-3.41)$ & $-2.77 * *$ & $(-3.36)$ \\
\hline \multicolumn{5}{|c|}{ First connection to a provincial capital } \\
\hline Private lines & $3.86^{* *}$ & $(4.62)$ & $3.77 * *$ & $(4.55)$ \\
\hline Private local lines & N/A & & N/A & \\
\hline State lines & -1.67 & $(-1.34)$ & -1.90 & $(-1.47)$ \\
\hline \multicolumn{5}{|l|}{ Connects border zone } \\
\hline Private lines & $3.45^{* *}$ & $(4.96)$ & $3.71 * *$ & $(5.26)$ \\
\hline Private local lines & -0.59 & $(-0.52)$ & -0.52 & $(-0.45)$ \\
\hline State lines & 0.06 & $(0.06)$ & -0.10 & $(-0.10)$ \\
\hline \multicolumn{5}{|l|}{ Connects sea harbour } \\
\hline Private lines & -0.35 & $(-0.53)$ & -0.43 & $(-0.64)$ \\
\hline Private local lines & -0.11 & $(-0.17)$ & -0.01 & $(-0.01)$ \\
\hline State lines & $1.46^{*}$ & $(2.15)$ & $1.41 *$ & $(2.11)$ \\
\hline McFadden's Pseudo- $\mathrm{R}^{2}$ & 0.57 & & 0.57 & \\
\hline AIC & 262.95 & & 265.37 & \\
\hline
\end{tabular}

Coefficients marked by $*$ are significant at the 0.05 level; those marked by $* *$ are significant at the 0.01 level. All others are not. In the provincial capital variable, coefficients for local lines are missing because of insufficient variance in the data. The coefficients are set to zero in the later modelling exercise. In Scenario A, $N=3160$; in Scenario B1, $N=3193$

indifferent to maximizing their returns on investment. We must note that the results of an alternative model specification that included passenger mileage change on the whole network in the return on investment yielded worse results for all operators 
(results available upon request). We thus conclude that, consistent with other findings (Xie and Levinson 2011), the various operators were primarily preoccupied with the results for their own network. While private lines increased the disparities in accessibility in the country, private local lines and state lines aimed to decrease those disparities. The state presumably had political aims to decrease disparities in accessibility. These aims were, clearly, further enforced through subsidies and loans that accompanied the local railway act. All parties aimed to connect their new investments to their own network. The poor significance values in case of regular private lines presumably are due to the relatively large number of operators starting new networks in the early stages of network development. Private investors were apparently indifferent to whether their networks connected to competitors, while, surprisingly, state investments actively avoided connecting to other networks. Establishing the first connection to provincial capitals was sought after by private investors. Connecting border zones (and, implicitly, foreign railway networks) was also sought after by private line investors. In contrast, connecting sea harbours was sought after only by the Dutch state, possibly to provide a stimulus to the Dutch ports or for defensive purposes. The lack of interest from private parties seems to confirm that in the Netherlands, there was a very limited market for the overland transport of goods (Filarski and Mom 2008).

\section{Simulation results}

The historically built network and the allocation results for various scenarios are plotted in Figs. 4 and 5. The modelling efforts have yielded networks that are particularly dense in the Western, most urbanized part of the country. In contrast, the northern, eastern and southern parts of the country are much less served. In particular, the southwest of the country seems to gain more investments than built in reality, while especially lines in the eastern and south-eastern parts of the country are underrepresented in the modelling results. An in-depth investigation of this bias is planned in follow-up research.

The differences in network shapes and network ownership are striking. In all cases, private lines mostly function as trunk lines, with the state providing peripheral extensions to the trunk network and local lines providing connections between trunk lines. With the exception of scenario C, local lines do not seem to have a dominant feeder function. The density of the trunk line network depends on overarching conditions: for example, with a lower value of $\phi$ the trunk network appears to be more extensive (cf. scenario A vs scenario B1). Interestingly, in the B2 variant, one operator obtains complete monopoly in the private lines and expands that network much more than happens in a more competitive setting (cf. scenario B1). Possibly the existence of greater network externalities allows for a greater density in the final network of the monopolist.

The total cumulative length of the historical and modelled networks is shown in Fig. 6. It is clear that after the first five investments or so, the model allocates network investments in smaller chunks than the historically built network, causing the lower per investment growth of the modelled networks. This bias deserves to be 


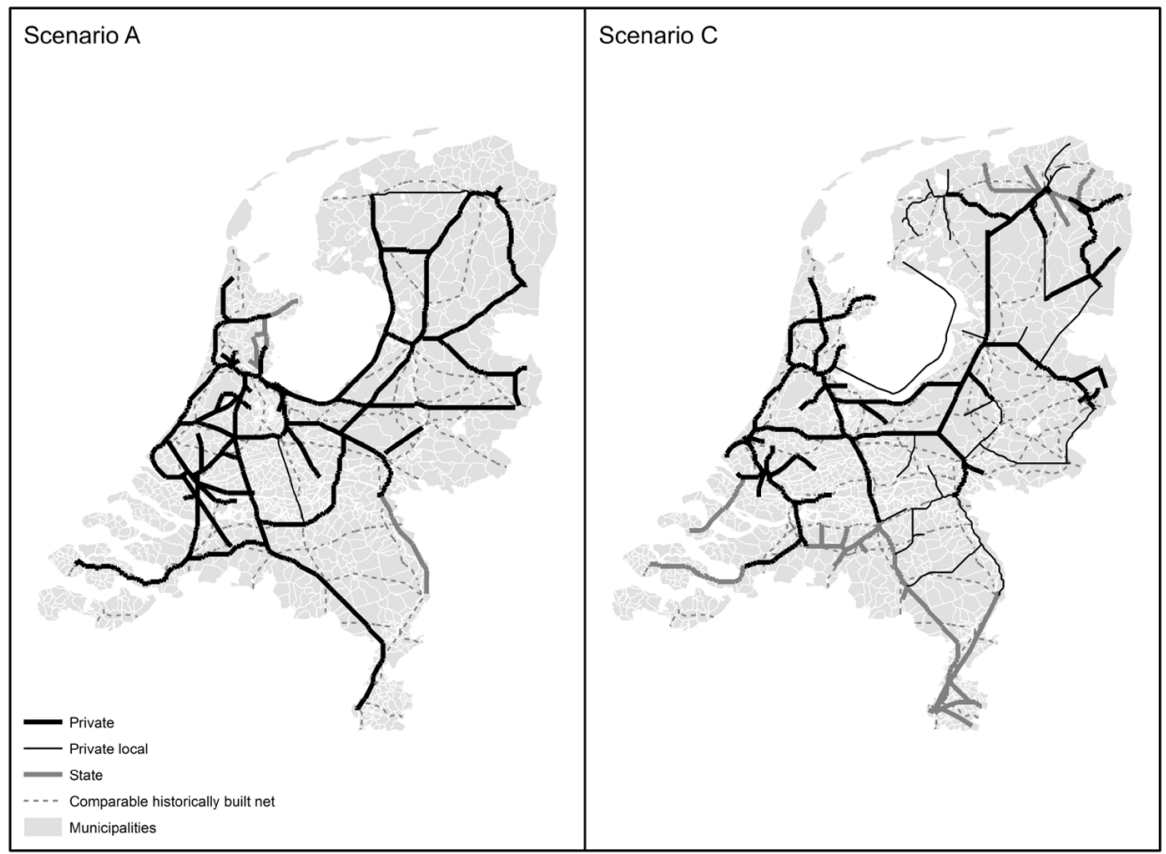

Fig. 4 TLS investment allocation results of the scenarios A and C

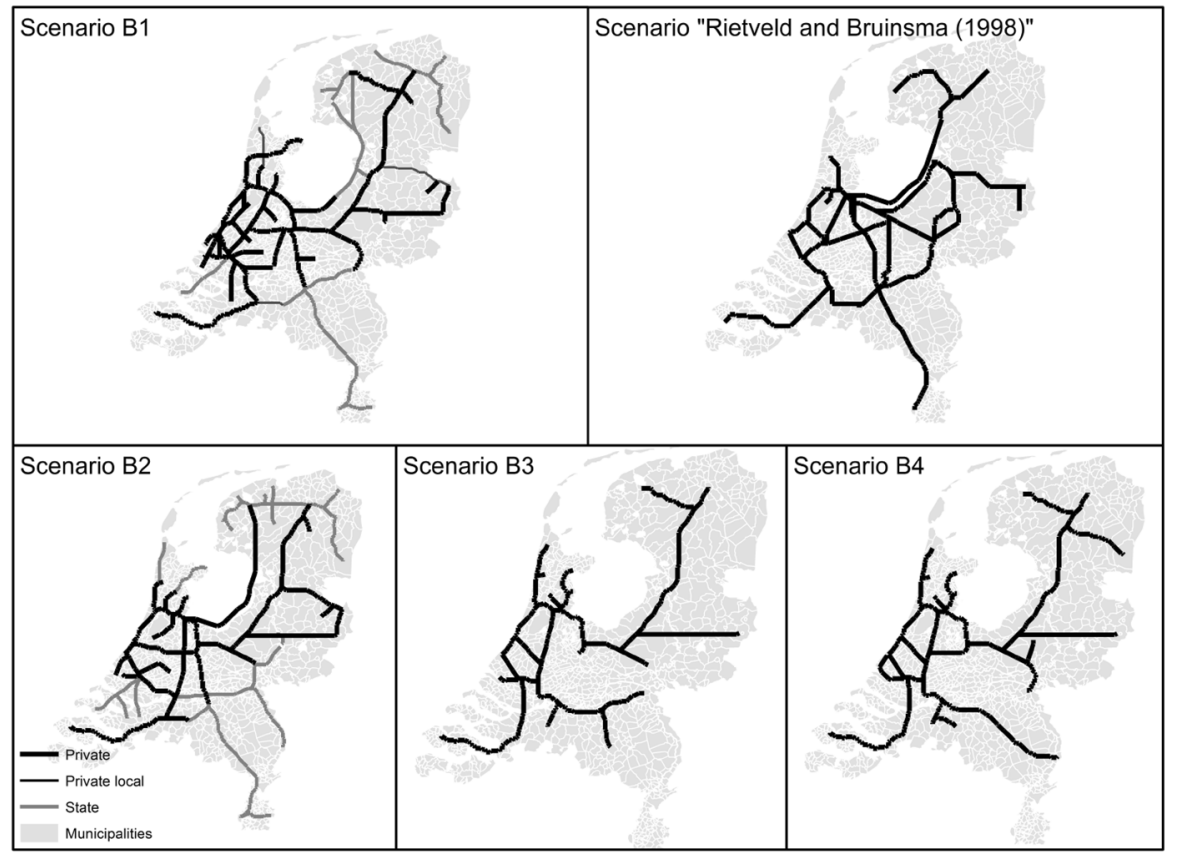

Fig. 5 TLS investment allocation results of Rietveld and Bruinsma (1998) and the B1, B2, B3, B4 scenario variants 

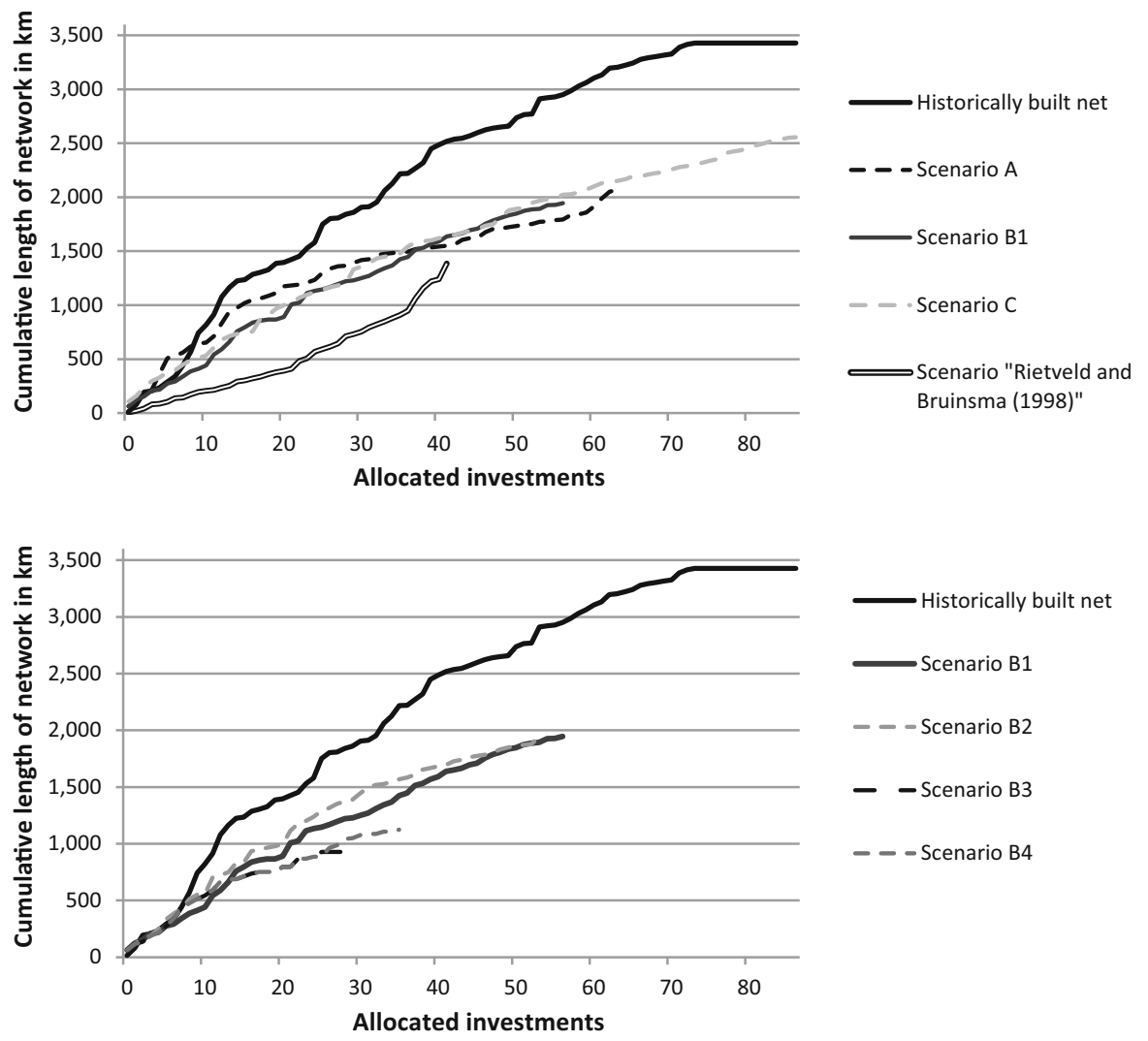

Fig. 6 Cumulative lengths of the modelled railway lines according to the scenarios A, B1 and C and the method proposed by Rietveld and Bruinsma (1998) (above); the cumulative lengths of modelled railway lines in the B1 to B4 scenarios (below). The cumulative length of the built network has been added to both graphs for comparison

tackled in follow-up research. In all cases, the modelled networks reach a smaller length than the historically built network. That the simulated networks are smaller is either because the modelling framework fails to provide sufficiently attractive alternatives, or because state involvement and the ensuing fierce competition on the Dutch railway network caused overinvestment in the network, as suggested by Knick Harley (1982) and Veenendaal (1995). The latter explanation is further supported by the B3 and B4 variants which restrict the playing field to two private parties that are mainly driven by return on investment. In these scenarios, the early depletion of additions that increase passenger mileage causes much shorter final networks. Additional evidence can be found in the breakdown of network lengths per operator type in Appendix 3, which shows a striking dominance of state-built lines in the historically built network. Lastly, lower growth and shorter final network length are particularly conspicuous in the Rietveld and Bruinsma network. The reasons for this are that method's known bias for short links (Rietveld and Bruinsma 1998) and the early depletion of the pool of 35 connectable cities. Experiments with 
removing the a priori selection of connectable cities failed, because the adapted method only yielded very short connections.

As noted before, two indicators were used in this paper to measure the relative geographic accuracy of the presented model. The computed accuracy indicators are plotted against investment sequences in Figs. 7 and 8. Comparing both accuracy indicators, two contradicting trends become apparent. Where travel-time errors increase as the railway network develops, connection errors decrease with network growth, as it becomes more likely the municipalities connected by the random network coincide with municipalities connected by the historical network. The simulation results start with a substantial increase in percentage travel-time error. These errors decrease after roughly $1250 \mathrm{~km}$ of allocated railway network. Both connection accuracy and travel-time errors remain relatively stable afterwards. This

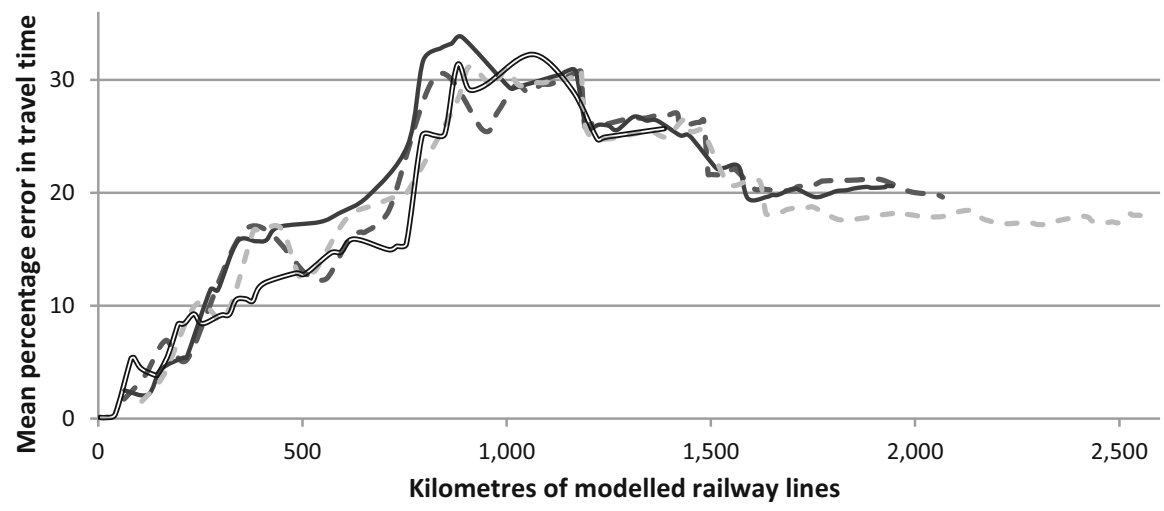

- - Scenario A Scenario B1 - - - Scenario C Scenario "Rietveld and Bruinsma (1998)"

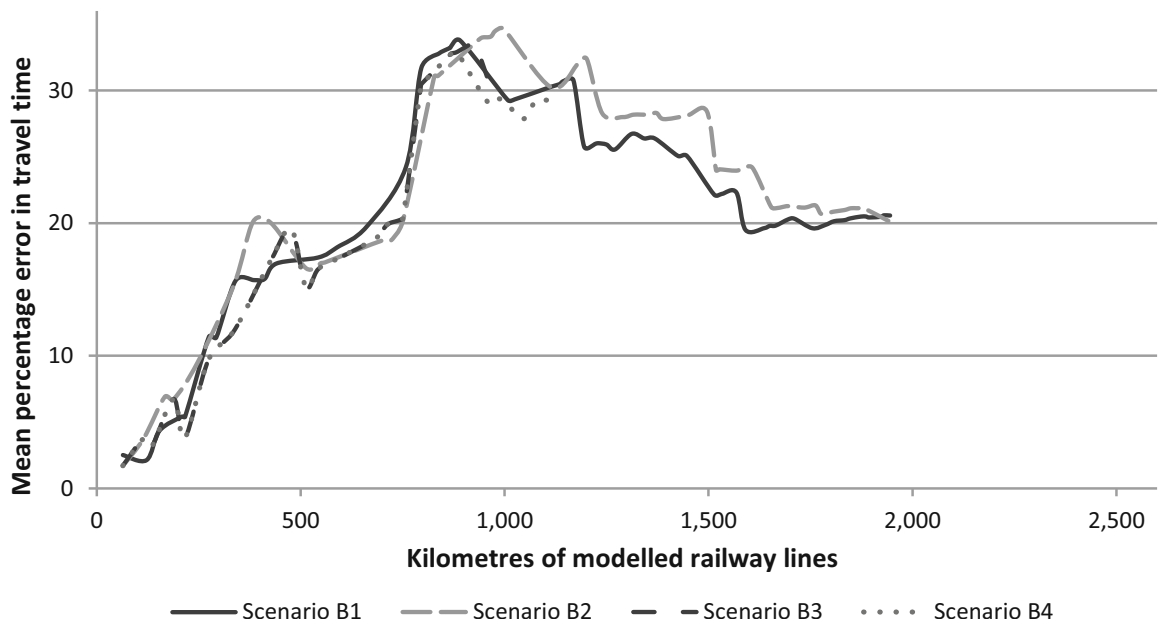

Fig. 7 Travel-time errors in the scenarios A, B1 and C and the method proposed by Rietveld and Bruinsma (1998) (above), and travel-time errors in the scenarios B1 to B4 (below). Travel-time errors are obtained by comparing with the result of the built network at an approximately similar length 
indicates that the model does a better job at reproducing the final form of the network than it does at the precise sequence of investments; it also shows implicitly that earlier network additions have a much larger impact on the distribution of travel times than last additions. We additionally note that, seemingly at odds with the variation in network shapes, model accuracy hardly changes between scenarios. This raises the question to what degree the presented weighted travel-time errors are affected by transport network shape.

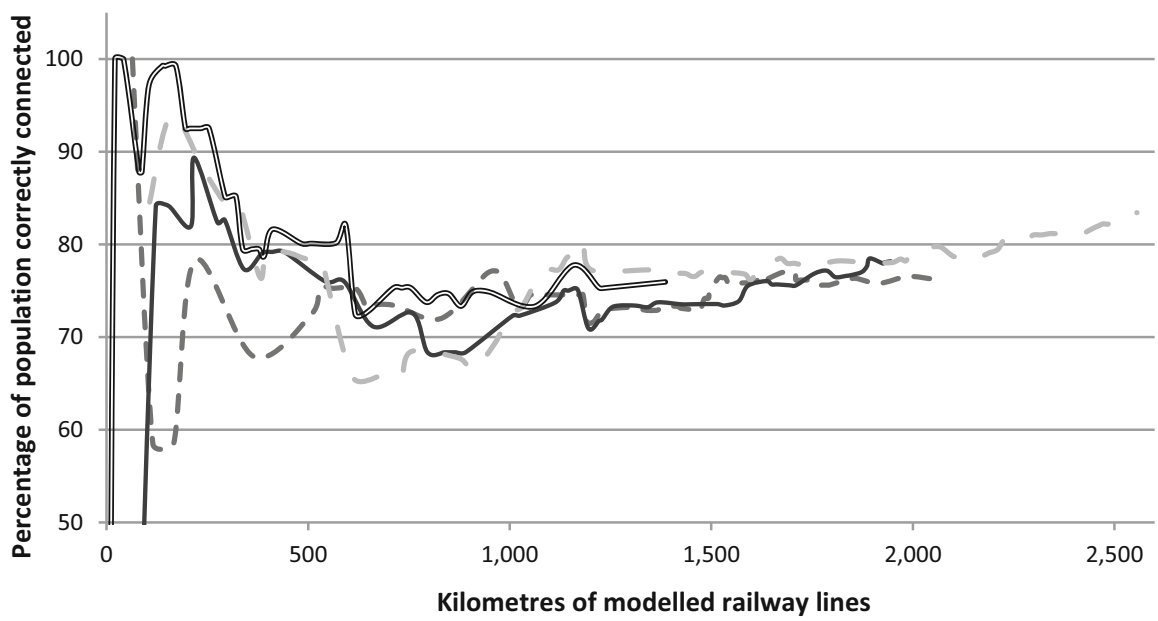

- - Scenario A Scenario B1 - Scenario C $\longrightarrow$ Scenario "Rietveld and Bruinsma (1998)"

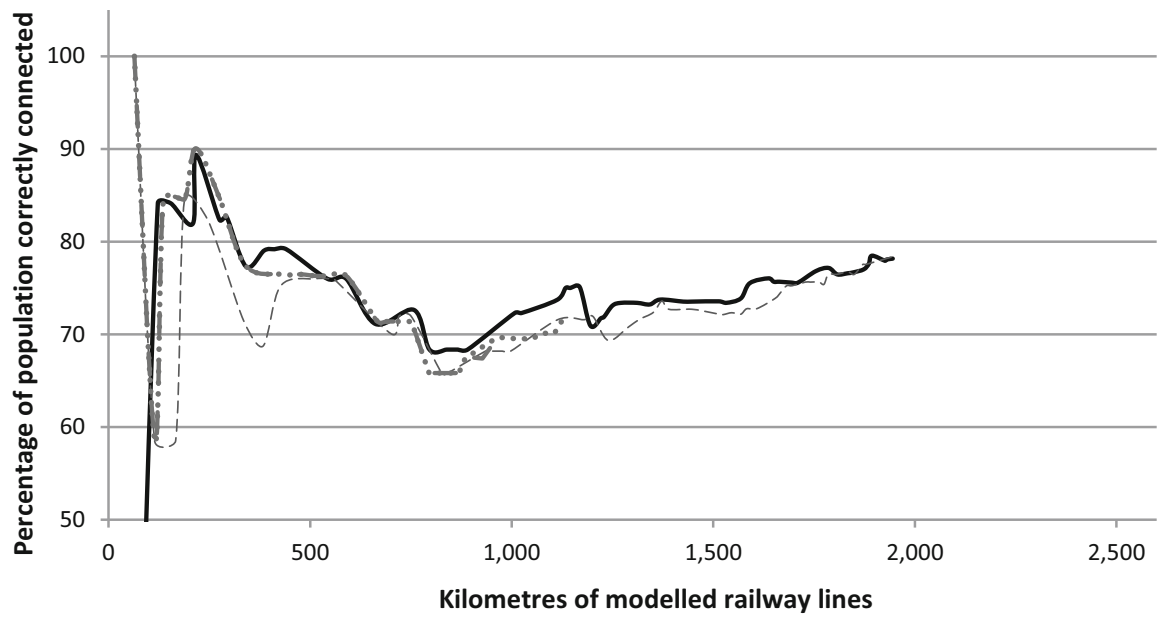

metres of moded railway lines

Scenario B1

Scenario B2 - - Scenario B3

Scenario B4

Fig. 8 Connection accuracy expressed as percentage of population correctly connected by railway lines in the scenarios A, B1, C and the method proposed by Rietveld and Bruinsma (1998) (above), and connection accuracy in the scenarios B1 to B4 (below). Connection accuracies are obtained by comparing with the result of the built network at an approximately similar length 


\section{Closing remarks}

This paper presents transport link scanner, a model that simulates the expansion of transport networks. Based on a conditional logit method, the model repeatedly selects one most attractive link from a choice set to add to the expanding network. That choice set is generated using heuristics with the goal to obtain a limited set of relevant, geographically plausible links. The model outlined in this paper explicitly allows the empirical estimation of preferences in a context with multiple actors with possibly different characteristics. It allows to test, amongst others, the impact of investor preferences, transport revenue structures and network effects on the final outcomes of a transport network.

A practical application of the model is presented as well. This exercise focuses on the expansion of the Dutch railway network in the nineteenth and early twentieth century and compares the model's accuracy with a previous attempt by Rietveld and Bruinsma (1998). The results presented show that the early expansion of the Dutch railway network is simulated by TLS with similar accuracy as by Rietveld and Bruinsma, without the necessity of an a priori selection of connectable cities. The results corroborate findings that transport network expansion follows a clear rationale (Rietveld and Bruinsma 1998; Xie and Levinson 2011; Levinson et al. 2012), show that the modelling rationale can simulate network expansion processes with some success and illustrate that institutional and economic settings may have a profound effect on network expansion outcomes. Future research may be necessary to further improve the accuracy of the model and measure its performance in terms of characteristic spatial network metrics (Rodrigue et al. 2006). One other useful addition would be the inclusion of socially optimal networks (Li et al. 2010) that would enable exploration of how competitive investment decisions can be directed towards social optima (Anshelevich et al. 2003). Nevertheless, we conclude that the model appears to become a useful tool for academic studies and policy evaluations.

Acknowledgements This work has profited immeasurably from the many inputs given by Piet Rietveld, whose untimely death has prevented him from seeing these final results. We must also thank Aart Huijg, Peter Groote, Maarten Hilferink, Martin van der Beek, the Dutch Railway museum and three anonymous reviewers, who have all had an important role in the preparation of this paper.

Open Access This article is distributed under the terms of the Creative Commons Attribution 4.0 International License (http://creativecommons.org/licenses/by/4.0/), which permits unrestricted use, distribution, and reproduction in any medium, provided you give appropriate credit to the original author(s) and the source, provide a link to the Creative Commons license, and indicate if changes were made. 


\section{Appendix 1: Transport link construction costs}

In the choice set generation and in the estimation of investment attractiveness, the construction costs of distinct investments come into play. In this study, the costs that are taken into account are a fixed cost and costs linked with the geography that the proposed link overcomes. For the sake of simplicity, the costs for maintenance, personnel and inventory are currently ignored in the model. In the case study, the costs of constructing a link have been estimated using an ordinary least squares (OLS) regression of the following equation:

$$
C_{l}=\beta_{0} \text { RIVER }_{l}+\beta_{1} \text { HARDSOILS }_{l}+\beta_{2} \text { SOFTSOILS }_{l}+\varepsilon
$$

in which guilders of recorded costs of nineteenth-century rail construction projects in the Netherlands are explained by a constant and traversed metres of river, hard and soft soils. The hard soils class contains gravel, sand and loam. The soft soils class contains clay and peat. The recorded costs describe the costs imbued by the Dutch state in a number of network expansions between 1860 and 1880. These costs have been inflated to the 1913 level and are assumed to be fixed (in real terms) over time. For the comparison of investment options, the geographic distribution of cost factors is much more important than temporal variations. Therefore, we expect that this assumption does not substantially affect the results of this article. The OLS estimation results are given in Table 3. Unfortunately, the exact locations of built-up land in the Netherlands in the nineteenth century and the costs of building railways through such built-up areas are not precisely known, so that we cannot model the presumably high costs of constructing railways in already urbanized areas. We note, however, that the Netherlands were a mainly rural country in the nineteenth century. Moreover, railway stations and railway lines were mainly built at the edges of the then existing cities.

Table 3 Estimated factors contributing to the costs of constructing a railway line

* Estimates significant at the 0.05 level. $N=38 . R^{2}=0.14$

\begin{tabular}{lcl}
\hline & \multicolumn{1}{c}{ Coefficient } & $t$ statistics \\
\hline Constant & $1,980,280.00^{*}$ & 2.39 \\
Meter of river & 2760.61 & 1.76 \\
Meter of hard soil & 12.38 & 0.55 \\
Meter of soft soil & $64.57^{*}$ & 2.57 \\
\hline
\end{tabular}




\section{Appendix 2: Passenger transport revenues}

We assume that all links in the Dutch railway network have been built for the purpose of maximizing passenger transport profits (Veenendaal 2008; Filarski and Mom 2008). Clearly, return on investment played an important role in the development of the Dutch railway network. Revenues of railway network construction are computed here as increases in passenger mileage on an investor's network. Estimating these returns requires repetitively estimating a spatial interaction model and allocating the resulting flows on various proposed network configurations. The spatial interaction model applied in the case study is based on empirically obtained parameters and, amongst others, the assumptions that: (1) increasing interaction opportunities cause growth in the propensity of people to travel and (2) no restrictions are imposed on the number of trips into zones because train travellers' motives for visiting specific zones are unknown. Alonso's GTM enables parameterization of the degree to which opportunities and competition or congestion affect demand and encompasses all variants of Wilson's family of spatial interaction models as special cases (De Vries et al. 2001). We do not take the effects of competition or congestion at the destination into account, so that we effectively apply:

$$
\begin{gathered}
T_{i j}^{*}=A_{i}^{(1-\gamma)} P_{i} P_{j} f\left(c_{i j}\right) \\
A_{i}=\left\{\sum_{j=1}^{n} B_{j}^{1-\theta} P_{j} f\left(c_{i j}\right)\right\}^{-1}
\end{gathered}
$$

where $T_{i j}^{*}$ represents observed passenger trips from $i$ to $j, A_{i}$ indicates origin-specific potential accessibility, $P$ is population size, and $f\left(c_{i j}\right)$ is a travel cost decay function. In the model, the number of trips going to a specific destination is not restricted, so that $\theta$ is set to one. The function $f\left(c_{i j}\right)$ and subsequently the value of $\gamma$ are estimated in two steps as proposed by De Vries et al. (2002). We first estimate $f\left(c_{i j}\right)$ by regressing the log specification of a singly constrained gravity model, as proposed by Fotheringham and O'Kelly (1989):

$$
\ln \left(T_{i j}^{*}\right)=\delta_{i} O_{i}+\alpha_{1} \ln \left(P_{j}\right)+\beta_{1} \ln \left(c_{i j}\right)+\varepsilon_{i j}
$$

where $c_{i j}$ denotes the shortest travel time from $i$ to $j$, and $O_{i}$ is an origin-specific fixed-effect dummy. To estimate this spatial interaction model that may include zero flow observations, we use $\ln \left(T_{i j}^{*}+0.5\right)$ to replace $\ln \left(T_{i j}^{*}\right)$ as suggested by Sen and Sööt (1981). We have estimated the distance-decay parameter in both exponential and power specifications of the distance-decay function. The latter consistently yielded better results. Data on travel flows were obtained from sold train tickets between the 14 stations on the Amsterdam to Rotterdam rail line (HSM 1889). These data are reproduced in Table 4 . We find that $f\left(c_{i j}\right)=s_{i j}^{-1.777}$ and use this to compute $A_{i}$, as defined in Eq. (22). Although changing the distance-decay parameter substantially influences absolute marginal returns, we find that the ratios of the 


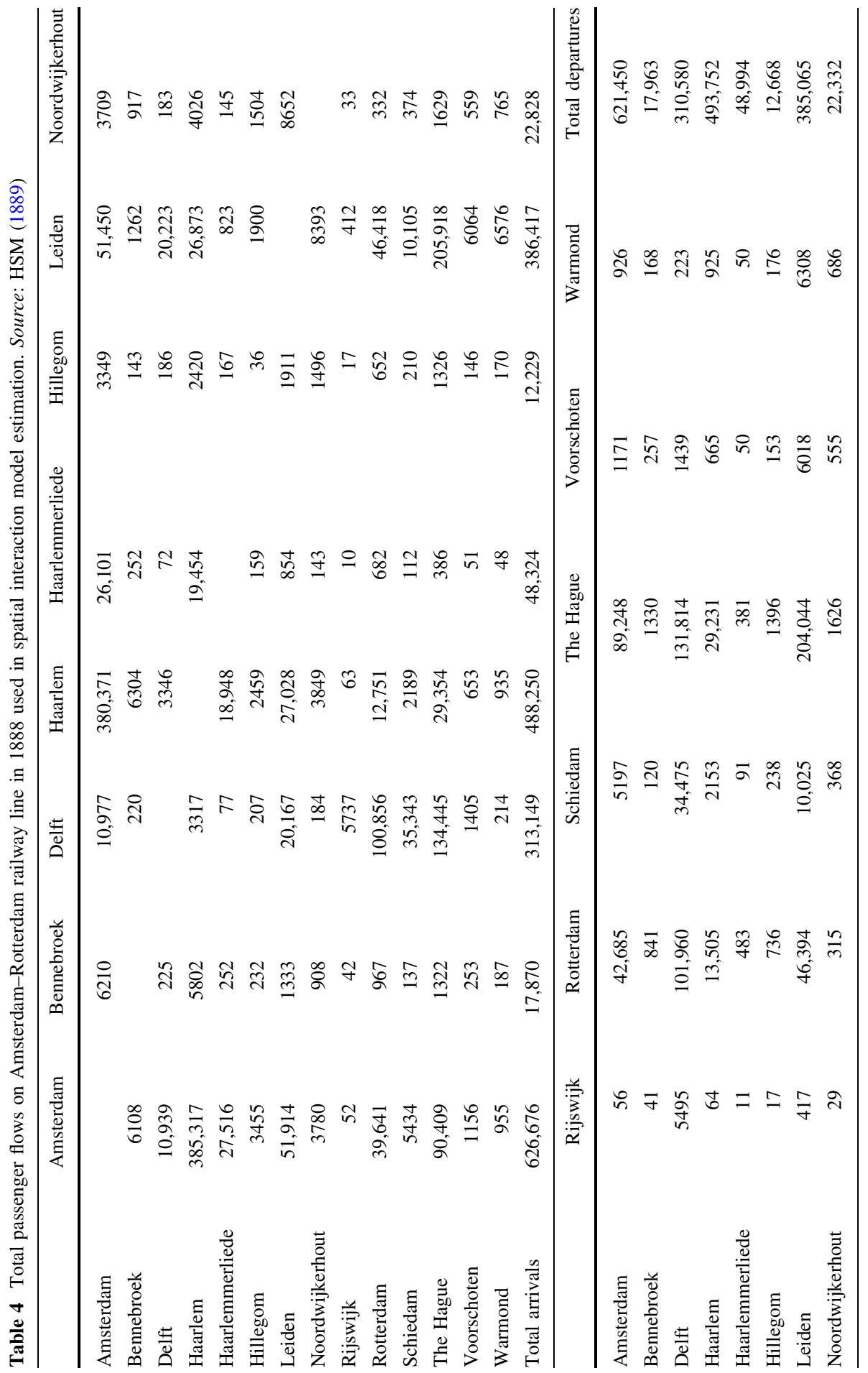




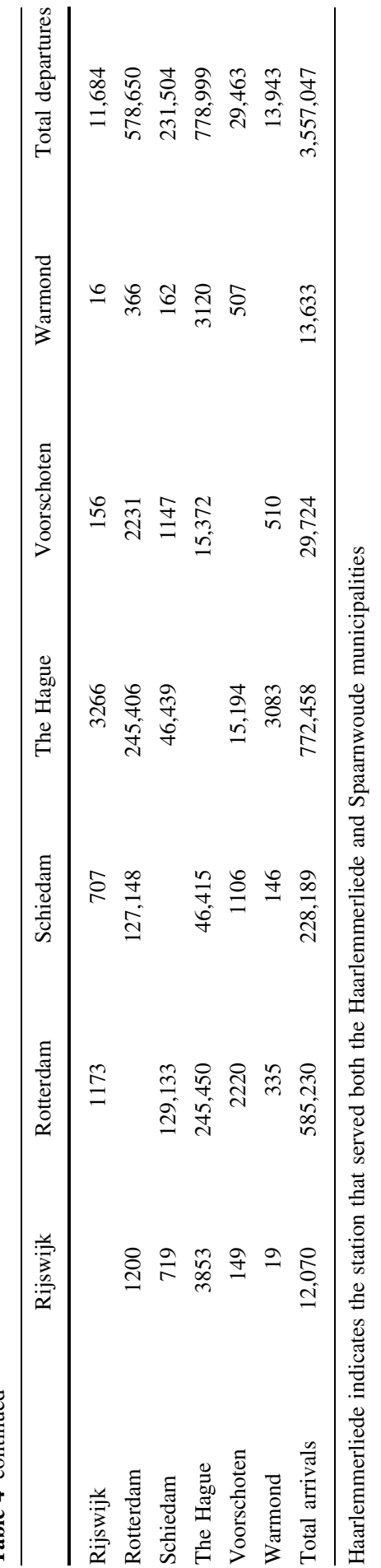


Table 5 Parameters estimated from sold railway tickets on the Amsterdam to Rotterdam line in 1888

\begin{tabular}{|c|c|c|c|c|c|c|}
\hline & $\alpha$ & $t$ & $\beta$ & $t$ & $R^{2}$ & $N$ \\
\hline \multirow[t]{2}{*}{ Equation (23) } & 0.825 & 26.33 & -1.777 & -18.97 & 0.989 & 182 \\
\hline & & & $\gamma$ & $t$ & $R^{2}$ & $N$ \\
\hline Equation (24) & - & - & 0.304 & 41.44 & 0.905 & 182 \\
\hline
\end{tabular}

All parameters are significant at the 0.01 level

marginal returns of different lines are hardly affected. The value of $\beta$ appears to have only a small impact on our findings. ${ }^{2}$ We subsequently regress:

$$
\ln \left(T_{i j}^{*}\right)-\ln \left(P_{i}\right)-\ln \left(P_{j}\right)-\ln \left(s_{i j}^{-1.777}\right)=(1-\gamma) \ln \left(A_{i}\right)+\varepsilon .
$$

All results of demand model estimation are presented in Table 5. T has a 0.3 elasticity to both accessibility and travel cost. This means that the total number of trips originating in $i$ increases when the accessibility of $i$ increases. To assess the impact of model specification on the results of the later choice analysis, we alternatively analyse link railway construction choices when changes in travel cost only cause substitution at the origin (i.e. $\gamma$ is set to zero), which implies that railway investments do not affect the total number of trips.

A multiple-path logit model is subsequently used to allocate flows to the network (see Stern and Bovy 1989):

$$
P_{r}=\frac{\exp V_{r}}{\sum_{h=1}^{n} \exp V_{h}}
$$

with $P_{r}$ being the probability that a traveller chooses path $r$; and $V_{r}$ and $V_{h}$ describing the travel values of path $r$ and all paths $h$, respectively. Alternative paths are generated by means of a link elimination method (Bekhor et al. 2006). In the case study, the utility of paths is defined as $V_{r}=\alpha\left(c_{r}\right)$, with $\alpha<0$ and $c$ indicating travel times. As the interaction data available for the case study do not allow estimation of the utility parameter, we resort to other literature. A parameter from Vrtic and Axhausen (2002) is applied, which is -2.398 (for hourly increases of travel time). We use this parameter in Eq. (25) because it is estimated on longer distance train trips, implying a similar context as in our study.

\section{Appendix 3: Results per operator type}

In this appendix, simulation results per operator type are discussed for the scenarios A, B1 and C, and where relevant also for the results of the Rietveld and Bruinsma (1998) model. The emphasis is put on scenario comparison and implications for network expansion modelling.

\footnotetext{
2 The results are available on request.
} 


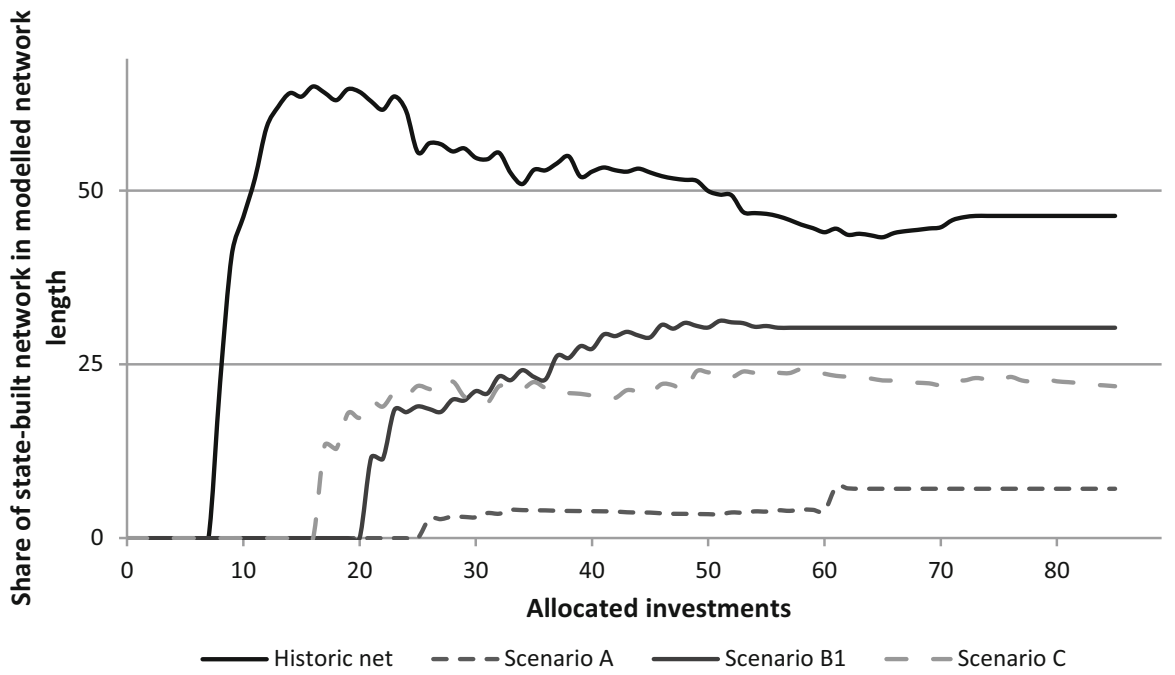

Fig. 9 Shares state-built network length in total network length

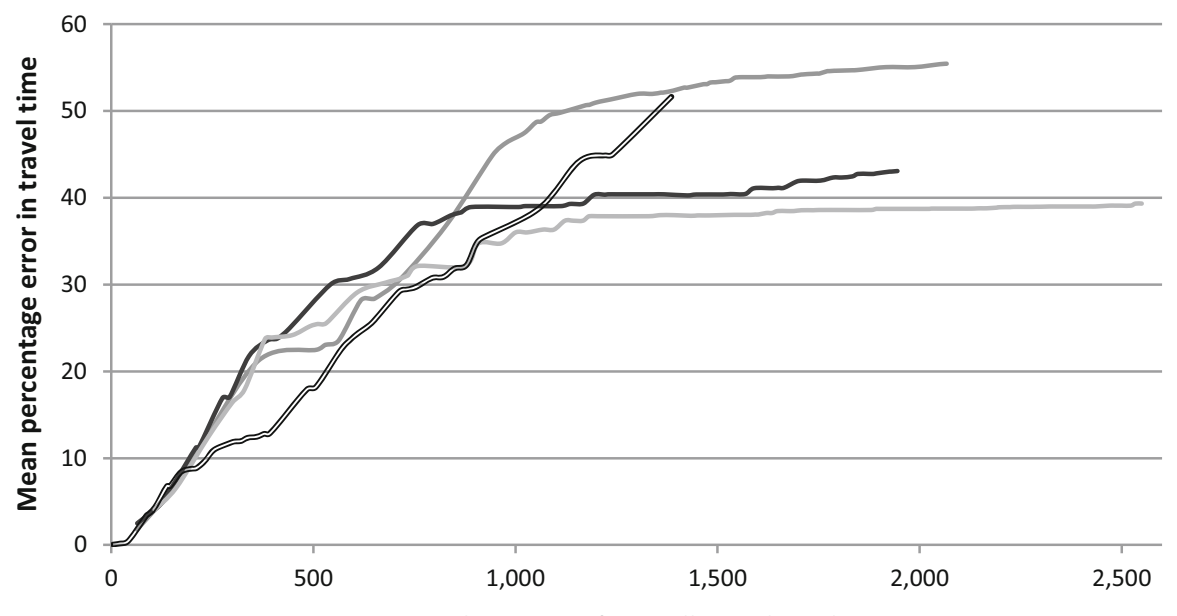

Kilometres of modelled railway lines

- Scenario A Scenario B1 Scenario C CScenario "Rietveld and Bruinsma (1998)"

Fig. 10 Mean percentage error in travel time on regular private railway lines

In Fig. 9, the lengths of the state-built network in the scenarios discussed are shown as shares of total network length. From the results, it is clear that, in contrast to the historically built network, all networks modelled obtain a much smaller share of state-built links. Larger values of $\phi$ result in larger state involvement, presumably because potential investments with good return on investment are depleted faster. The very early onset of state involvement in the historically built network is 


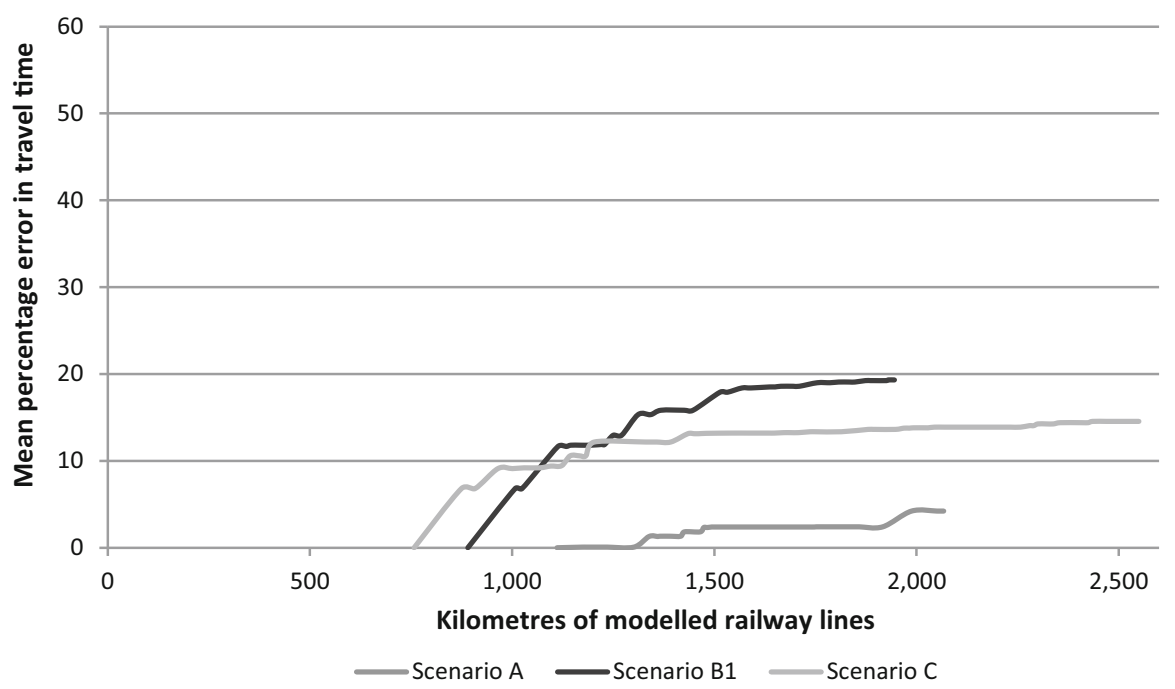

Fig. 11 Mean percentage error in travel time on state-built lines

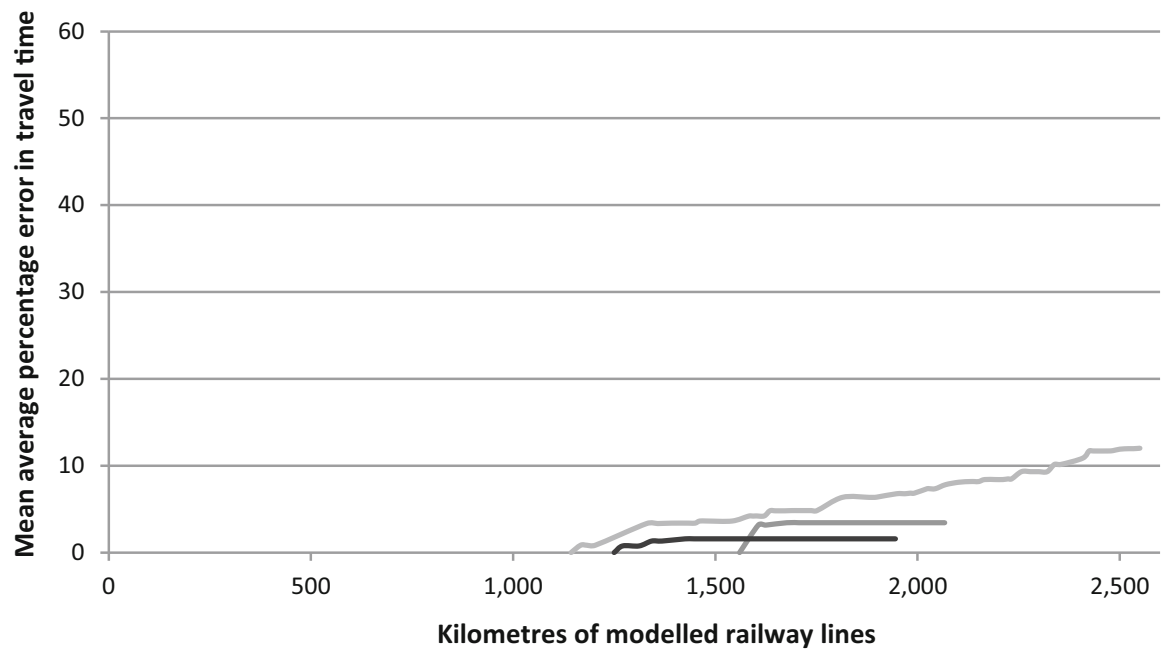

Scenario A Scenario B1 Scenario C

Fig. 12 Mean percentage error in travel time on local private lines

particularly striking. State involvement was relatively early because network expansion in the study area was particularly slow at the start (see Veenendaal 1995). This was the case either because of market imperfections left out of consideration, or because of the almost exclusive reliance of the transport network on passenger transport that yielded poor absolute revenues.

Figures 10,11 and 12 show the mean errors in travel time when only considering the networks built for regular private lines, state lines and local private lines, 
respectively. The travel times on the subnets are compared with similar subnets of the historically built network in which the total reference network is about as long as the total network modelled. Thus, the demonstrated mean errors reflect both discrepancies in shares per operator type and errors in travel times modelled. From these results, it is clear that the scenarios $\mathrm{B} 1$ and $\mathrm{C}$ are the best performers, thus leading to the conclusion that a value of $\varphi$ of at least five has been obtained by the railways. When comparing the different operator types, the population-weighted errors presented here mostly reflect the transport relevance of the various operator types. Regular private lines served the largest cities, and network allocation errors on the regular private networks consequently cause emphasized relative errors. In contrast, the errors on state and local lines have a much lower weight.

\section{Appendix 4: Nomenclature}

\begin{tabular}{|c|c|}
\hline$A_{i}$ & Interaction options at the origin (destination accessibility) \\
\hline Alternative & Potential addition to the network represented by a link \\
\hline Base & $\begin{array}{l}\text { Network before introduction of modelled transport mode or characteristic of existing } \\
\text { transport mode }\end{array}$ \\
\hline$B_{j}$ & Interaction options at the destination (origin accessibility) \\
\hline$C$ & Construction costs of link or segment \\
\hline$c$ & Generalized travel cost of link or segment \\
\hline $\mathrm{cp}$ & Penalty for entering and exiting the introduced transport mode \\
\hline curr & Network state at start of model iteration \\
\hline $\operatorname{est}(x)$ & $\begin{array}{l}\text { Estimated network state with treated investment choice in place (multiple versions } \\
\text { indicated by } x \text { ) }\end{array}$ \\
\hline$i$ & Origin municipality \\
\hline INEQACC & Changes in the Theil's index of accessibility due to a considered investment option \\
\hline intr & Characteristic of introduced transport mode \\
\hline Investor & Agent deciding on investments and obtaining revenues from the investment \\
\hline$j$ & Destination municipality \\
\hline$k$ & Parameter used while iterating plausible paths with changing importance of path length \\
\hline$L$ & Length of link or segment \\
\hline Link $(l)$ & Connection between two municipalities $(i$ and $j$ ) physically represented by a path \\
\hline MS & $\begin{array}{l}\text { Market saturation of } i \text { or } j \text {, computed as potential number of trips to be gained from link } \\
\text { connection given the current and future network state }\end{array}$ \\
\hline Operator & Agent deciding on investments and obtaining revenues from the investment \\
\hline Option & $\begin{array}{l}\text { Potential addition to the network represented by a link, considered for investment by an } \\
\text { investor }\end{array}$ \\
\hline$P$ & Municipal population \\
\hline Path & Combination of segments that forms the physical representation of an alternative \\
\hline$R$ & $\begin{array}{l}\text { Crudely estimated revenues of a link or segment, instrumental in the generation of plausible } \\
\text { paths, computed by averaging connected population multiplied with MS }\end{array}$ \\
\hline $\mathrm{RC}$ & $\begin{array}{l}\text { Revenue-cost indicators per segment, instrumental in the generation of plausible paths, } \\
\text { computed as ratio of } R \text { versus } C\end{array}$ \\
\hline
\end{tabular}




\begin{tabular}{|c|c|}
\hline RCR & $\begin{array}{l}\text { Factor to be optimized in choice set generation computed as ratio of estimated increase in } \\
\text { passenger mileage versus the costs of link construction }\end{array}$ \\
\hline ROI & $\begin{array}{l}\text { An alternative's expected return on investment, computed as the ratio between estimated } \\
\text { transport flows on the investor's network and the costs of constructing the alternative }\end{array}$ \\
\hline $\begin{array}{l}\text { Segment } \\
(s)\end{array}$ & Individual, unseparable lines from which paths are composed \\
\hline$T$ & Trips between municipalities $i$ and $j$ \\
\hline$V$ & Speed of transport mode \\
\hline WCE & Population-weighted connection error, used as accuracy indicator \\
\hline WMAPE & $\begin{array}{l}\text { Population-weighted average errors in travel times between municipalities, used as } \\
\text { accuracy indicator }\end{array}$ \\
\hline$Z$ & $\begin{array}{l}\text { Selection dummy used to obtain a limited set of alternatives in the first step of choice set } \\
\text { generation }\end{array}$ \\
\hline$B$ & Parameter governing distance-decay model \\
\hline$\gamma$ & Parameter governing transport consumption elasticity to travel cost at the origin \\
\hline$\delta$ & Parameter governing trip production for each municipality as a fixed effect \\
\hline$\vartheta$ & Parameter governing congestion effects at destination on destination attractiveness \\
\hline$\phi$ & Parameter indicating relative travel cost decrease offered by introduced transport mode \\
\hline
\end{tabular}

\section{References}

Alonso W (1978) A theory of movements. In: Hansen NM (ed) Human settlement systems: international perspectives on structure, change and public policy. Ballinger, Cambridge, pp 197-211

Anshelevich E, Dasgupta A, Tardos E, Wexler T (2003) Near-optimal network design with selfish agents. In: Proceedings of the thirty-fifth annual ACM symposium on theory of computing, ACM, San Diego, 9-11 June 2003, pp 511-520

Bala V, Goyal S (2000) A noncooperative model of network formation. Econometrica 68(5):1181-1229

Baranzelli C, Jacobs-Crisioni C, Batista F, Castillo CP, Barbosa A, Torres JA, Lavalle C (2014) The reference scenario in the LUISA platform-updated configuration 2014 towards a common baseline scenario for EC impact assessment procedures. Report EUR 27019 EN. Publications Office of the European Union, Luxembourg

Bekhor S, Ben-Akiva ME, Ramming MS (2006) Evaluation of choice set generation algorithms for route choice models. Ann Oper Res 144(1):235-247

De Rigo D, Corti P, Caudullo G, McInerney D, Di Leo M, San Miguel-Ayanz J (2013) Toward open science at the European scale: geospatial semantic array programming for integrated environmental modelling. Geophys Res Abstr 15:13245

De Vries JJ, Nijkamp P, Rietveld P (2001) Alonso's theory of movements: developments in spatial interaction modeling. J Geogr Syst 3(3):233-256

De Vries JJ, Nijkamp P, Rietveld P (2002) Estimation of Alonso's theory of movements by means of instrumental variables. Netw Spat Econ 2(2):107-126

Dobbin F, Dowd TJ (1997) How policy shapes competition: early railroad foundings in Massachusetts. Adm Sci Q 42(3):501-529

Doedens A, Mulder L (1989) Een spoor van verandering: Nederland en 150 jaar spoorwegen. Bosch \& Keuning, Baarn

Donaghy KP (2010) Models of travel demand with endogenous preference change and heterogeneous agents. J Geogr Syst 13(1):17-30

Economides E (1996) The economics of networks. Int J Ind Organ 14(2):673-699

Filarski R, Mom G (2008) Van transport naar mobiliteit: de transportrevolutie 1800-1900. Walburg, Zutphen 
Fotheringham AS, O'Kelly ME (1989) Spatial interaction models: formulations and applications. Kluwer, Dordrecht

Goodchild MF (1977) An evaluation of lattice solutions to the corridor location problem. Environ Plan A 9(7):727-738

Grübler A (1990) The rise and fall of infrastructures. Dynamics of evolution and technological change in transport. Physica Verlag, Heidelberg

Guevara CA, Ben-akiva ME (2013) Sampling of alternatives in multivariate extreme value (MEV) models. Transp Res Part B 48(1):31-52

Hilferink M, Rietveld P (1999) Land use scanner: an integrated GIS based model for long term projections of land use in urban and rural areas. J Geogr Syst 1(2):155-177

HSM (1889) Financieel verslag over dienstjaar 1888. Metzler \& Basting, Amsterdam

Jacobs-Crisioni C, Batista e Silva F, Lavalle C, Baranzelli C, Barbosa A, Castillo CP, Perpiña Castillo C (2016) Accessibility and territorial cohesion in a case of transport infrastructure improvements with endogenous population distributions. Eur Transp Res Rev 8(9):1-16

Knick Harley C (1982) Oligopoly agreement and the timing of American railroad construction. J Econ Hist 42(4):797-823

Kolars J, Malin HJ (1970) Population and accessibility: an analysis of Turkish railroads. Geogr Rev 60(2):229-246

Koopmans C, Rietveld P, Huijg A (2012) An accessibility approach to railways and municipal population growth, 1840-1930. J Transp Geogr 25(1):98-104

Kossmann EH (1986) De lage landen 1780-1980: Twee eeuwen Nederland en België. Elsevier, Amsterdam

Levinson D, Karamalaputi R (2003) Induced supply: a model of highway network expansion at the microscopic level. J Transp Econ Policy 37(3):297-318

Levinson D, Xie F (2011) Does first last? The existence and extent of first mover advantages on spatial networks. J Transp Land Use 4(2):47-69

Levinson D, Xie F, Oca NM (2012) Forecasting and evaluating network growth. Netw Spat Econ 12(2):239-262

Li G, Reis SDS, Moreira AA, Havlin S, Stanley HE, Andrade JS (2010) Towards design principles for optimal transport networks. Phys Rev Lett 104(018701):1-4

McFadden D (1974) Conditional logit analysis of qualitative choice behavior. In: Zarembka P (ed) Frontiers in econometrics. Academic Press, New York, pp 105-142

Morrill RL (1970) The spatial organization of society. Duxbury Press, Belmont

Nakicenovic N (1995) Overland transportation networks: history of development and future prospects. In: Batten D, Casti J, Thord R (eds) Networks in action. Springer, Heidelberg, pp 195-228

ObjectVision (2014) Geo data and model server (GeoDMS). http://objectvision.nl/geodms. Accessed 30 Mar 2016

Patriksson M (2008) Robust bi-level optimization models in transportation science. Philos Trans R Soc A 366(1872):1989-2004

Patuelli R, Arbia G (2013) Editorial: advances in the statistical modelling of spatial interaction data. J Geogr Syst 15(3):229-231

Rietveld P, Bruinsma F (1998) Is transport infrastructure effective?. Springer, Berlin

Rodrigue J-P, Comtois C, Slack B (2006) The geography of transport systems, 2nd edn. Routledge, London

Scaparra M, Church R, Medrano FA (2014) Corridor location: the multi-gateway shortest path model. J Geogr Syst 16(3):287-309

Sen A, Sööt S (1981) Selected procedures for calibrating the generalized gravity model. Pap Reg Sci Assoc 48(1):165-176

Stationsweb (2009) Information on stations in the Netherlands. http://www.stationsweb.nl. Accessed 5 May 2016

Stern E, Bovy PHL (1989) Theory and models of route choice behaviour. Research Institute of Urban Planning and Architecture, Delft

Taaffe EJ, Morrill RL, Gould PR (1963) Transport expansion in underdeveloped countries: a comparative analysis. Geogr Rev 53(4):503-529

Veenendaal AJ (1995) State versus private enterprise in railway building in the Netherlands, 1838-1938. Bus Econ Hist 24(1):186-193

Veenendaal AJ (2008) Spoorwegen in Nederland, 2nd edn. Boom, Amsterdam 
Vitins BJ, Axhausen KW (2009) Optimization of large transport networks using the ant colony heuristic. Comput Civ Infrastruct Eng 24(1):1-14

Vrtic M, Axhausen KW (2002) The impact of tilting trains in Switzerland: A route choice model of regional- and long distance public transport trips. Institut für Verkehrsplanung und Transportsysteme, ETH Zürich, Zürich

Warntz W (1966) The topology of a socio-economic terrain and spatial flows. Pap Reg Sci Assoc $17(1): 47-61$

Xie F, Levinson DM (2007) Jurisdictional control and network growth. Netw Spat Econ 9(3):459-483

Xie F, Levinson D (2009) Modeling the growth of transportation networks: a comprehensive review. Netw Spat Econ 9(3):291-307

Xie F, Levinson D (2011) Evolving transportation networks. Springer, New York

Youn H, Gastner MT, Jeong H (2008) The price of anarchy in transportation networks: efficiency and optimality control. Phys Rev Lett 101(128701):1-4 